\title{
Snowfall in the Himalayas: an uncertain future from a little-known past
}

\author{
E. Viste and A. Sorteberg \\ Geophysical Institute, University of Bergen, and Bjerknes Centre for Climate Research, Allégaten 70, 5007 Bergen, Norway \\ Correspondence to: E. Viste (ellen.viste@uib.no)
}

Received: 4 December 2014 - Published in The Cryosphere Discuss.: 19 January 2015

Revised: 14 April 2015 - Accepted: 4 May 2015 - Published: 2 June 2015

\begin{abstract}
Snow and ice provide large amounts of meltwater to the Indus, Ganges and Brahmaputra rivers. This study combines present-day observations and reanalysis data with climate model projections to estimate the amount of snow falling over the basins today and in the last decades of the 21 st century. Estimates of present-day snowfall based on a combination of temperature and precipitation from reanalysis data and observations vary by factors of $2-4$. The spread is large, not just between the reanalysis and the observations but also between the different observational data sets. With the strongest anthropogenic forcing scenario (RCP8.5), the climate models project reductions in annual snowfall by 30 $50 \%$ in the Indus Basin, 50-60\% in the Ganges Basin and $50-70 \%$ in the Brahmaputra Basin by 2071-2100. The reduction is due to increasing temperatures, as the mean of the models show constant or increasing precipitation throughout the year in most of the region. With the strongest anthropogenic forcing scenario, the mean elevation where rain changes to snow - the rain/snow line - creeps upward by $400-900 \mathrm{~m}$, in most of the region by 700-900 meters. The largest relative change in snowfall is seen in the upper westernmost sub-basins of the Brahmaputra. With the strongest forcing scenario, most of this region will have temperatures above freezing, especially in the summer. The projected reduction in annual snowfall is $65-75 \%$. In the upper Indus, the effect of a warmer climate on snowfall is less extreme, as most of the terrain is high enough to have temperatures sufficiently far below freezing today. A $20-40 \%$ reduction in annual snowfall is projected.
\end{abstract}

\section{Introduction}

In the dry spring months preceding the Indian summer monsoon, much of the water in the Himalayan rivers comes from melting snow and ice (Bookhagen and Burbank, 2010; Siderius et al., 2013; Schaner et al., 2012). Concern has been raised that global warming may reduce the glaciers and their capacity to store water as well as the amount of seasonal snow available for melting. Whether the meltwater comes from snow or glacier ice, stable snowfall is required to maintain the flow in the long run. Observations of presentday snowfall in the region are limited, meaning that there is also limited knowledge of the normal state and of historical trends. In this study we use temperature and precipitation data from a reanalysis and from observations to estimate snowfall in the Indus, Ganges and Brahmaputra basins today. We then incorporate the projected changes in temperature and precipitation from a suite of climate models and follow the same procedure to estimate snowfall in 2071-2100.

The catchments of the Indus, Ganges and Brahmaputra rivers, as referred to in this article, are shown in Fig. 1. The rivers run from the Hindu Kush-Karakoram-Himalaya $(\mathrm{HKH})$ mountain range through the lowlands of Pakistan, India and Bangladesh. Both rainwater and meltwater from snow and ice contribute to all three rivers, with the highest meltwater fraction in the Indus and the lowest in the Ganges (Immerzeel et al., 2010; Bookhagen and Burbank, 2010; Singh et al., 1997). Even in the Ganges, meltwater is important in the otherwise dry spring (Siderius et al., 2013).

Precipitation varies greatly between inner and outer parts of the Himalayas (Singh et al., 1997; Bookhagen and Burbank, 2006; Winiger et al., 2005). While there are regions in the Himalayan foothills and along the Himalayan ridge with an annual mean rainfall of more than $4000 \mathrm{~mm}$, most 


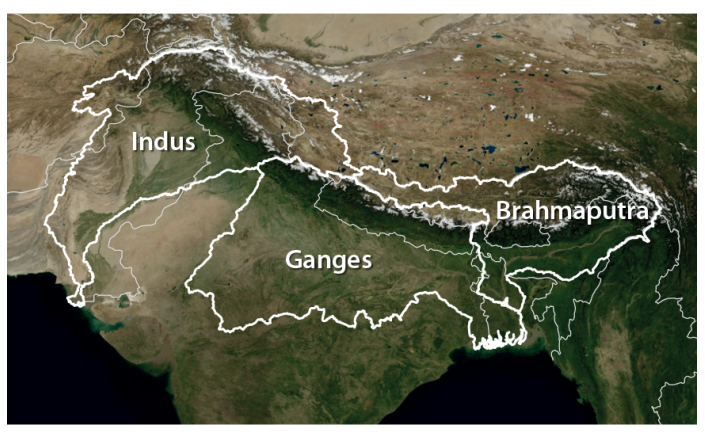

Figure 1. Map of the region, with the Indus, Ganges and Brahmaputra basins outlined in white. Thinner outlines are national borders. Background: NASA Visible Earth.

of the Tibetan Plateau on the leeward side receives less than $500 \mathrm{~mm}$ (Bookhagen and Burbank, 2010).

The Indian summer monsoon creates markedly different seasonal cycles in eastern and western parts of the $\mathrm{HKH}$, both in precipitation and in the accumulation of snow and ice. In the monsoon-dominated central Himalayas and on the Tibetan Plateau, more than $80 \%$ of the annual precipitation falls during summer. Precipitation maxima in the western regions occur in connection with westerly disturbances in winter. In the Hindu Kush and Karakoram, as well as in the easternmost Himalaya, summer precipitation amounts to less than $50 \%$ of the annual precipitation (Bookhagen and Burbank, 2010). The seasonal cycle of snowfall varies accordingly. In the western $\mathrm{HKH}$, snow accumulates during winter, while the summer is the main melting season. Further east, the summer is the main season not just for ablation but also for accumulation (Rees and Collins, 2006). According to Bookhagen and Burbank (2010), the east-west gradient and the effect of the summer monsoon is most pronounced in the lowlands, below $500 \mathrm{~m}$ a.s.l., while the difference is less at higher elevations.

\subsection{Observed trends in snowfall, temperature and precipitation}

Using satellite data, Rikiishi and Nakasato (2006) found that the mean annual snow cover area in the Himalaya and on the Tibetan Plateau had been reduced by $\sim 1 \% \mathrm{yr}^{-1}$ during 1966-2001. Few studies include snowfall data from stations on the ground, especially for periods long enough to detect trends. Studies of temperature and precipitation provide some information, though the picture is far from complete. Temperatures have increased in most of the region, whereas precipitation studies show varying results depending on the location and time period. Whereas higher temperatures act to reduce the snow fraction, increased precipitation may have compensated in some regions.

Positive temperature trends have been observed throughout the HKH (Immerzeel, 2008; Xu et al., 2008b; Bhutiyani et al., 2007, 2010; Immerzeel et al., 2009; Shrestha et al., 1999; Shekhar et al., 2010; Fowler and Archer, 2006). The only exception to the regional warming is the Karakoram range, where both maximum and minimum temperatures have decreased since the mid-1980s (Shekhar et al., 2010). Both in Nepal (Shrestha et al., 1999) and the Upper Indus (Immerzeel et al., 2009), temperatures have increased more at higher elevations than in the lower terrain, implying that regions with snow may have been more strongly affected than indicated by regional means.

Increasing temperatures (Xu et al., 2008b) have most likely been the driver behind reductions in the snow cover on the Tibetan Plateau. During 1966-2001, the length of the snow season was reduced by 23 days (Rikiishi and Nakasato, 2006). The annual precipitation on most of the Tibetan Plateau increased over the same period (Xu et al., 2008a, b; You et al., 2008); only in the western part was there a decrease (Xu et al., 2008b).

Few studies include data from the high-elevation parts of the Brahmaputra and Ganges basins. Immerzeel (2008) found no clear precipitation trends for Brahmaputra as a whole for 1901-2002. For the same period, Guhathakurta and Rajeevan (2008) found no significant precipitation trends relevant to snowfall in eastern parts of India, and neither did Shrestha et al. (2000) for stations in Nepal in the shorter period 1959-1994.

More studies of snow and ice have been performed for the Indus Basin than for the Ganges and Brahmaputra, possibly because meltwater constitutes a larger fraction of the runoff in this basin (Bookhagen and Burbank, 2010; Immerzeel et al., 2010). Also, as large parts of the Indus get little rain in late spring and summer, the link between melting snow and river discharge is perhaps more intuitive than in the regions further east, where the top of the meltwater season coincides with the Indian summer monsoon rain (Rees and Collins, 2006). No consistent precipitation trends have been found for the mountain regions of the Indus Basin as a whole, and epochs of more and less precipitation have alternated (Sontakke et al., 2008; Bhutiyani et al., 2010).

Some of the recent interest may also have been sparked by Karakoram glacier growth. After decades of recession, Karakoram glaciers were seen to expand in the late 1990s (Scherler et al., 2011; Gardelle et al., 2012; Hewitt, 2005). An observed combination of increased winter precipitation and decreased summer temperatures have been suggested to be the cause (Archer and Fowler, 2004; Fowler and Archer, 2006), and reduced summer discharge in rivers coming from the Karakoram is in accordance with the observed glacier growth (Fowler and Archer, 2006; Sharif et al., 2013). In contrast, Hartmann and Andresky (2013), found only insignificant negative trends in Karakoram precipitation during 1986-2010, and Cook et al. (2013) reported increased discharge in the Upper Indus after 1998. As pointed out by Hewitt (2005) and supported by Kääb et al. (2012), the glacier growth applies only to higher elevations in the central 
Karakoram, while glaciers in other parts and at intermediate elevations have continued to decline. Increased transport of moisture to higher altitudes may be part of the explanation (Hewitt, 2005).

Comparing the Karakoram with three other mountain ranges in the western Himalayas during 1984-2008, Shekhar et al. (2010) found that snowfall had been reduced in all the ranges, though less in the innermost Karakoram than in the outer ranges. As opposed to temperature increases in the other ranges, the Karakoram range experienced decreasing temperatures. The reduction in snowfall on the outside of the outermost range, Pir Panjal, during the last decades was supported by Bhutiyani et al. (2010), who found that the duration of the snowfall season had been reduced by about 5-6 days per decade.

Documented trends in other parts of the Indus basin vary, and alternating epochs indicate that the choice of time period may influence the results. In Jammu and Kashmir and Himachal Pradesh, Bhutiyani et al. (2010) found a significant decreasing trend in summer precipitation during the 20th century. There was no trend in winter precipitation at the three stations used, but epochs of dry and wet winters had alternated, and winter precipitation was above average in 1991-2006. Previously, a long-term increase in summer and annual precipitation in Jammu and Kashmir was documented by Guhathakurta and Rajeevan (2008) and in Himachal Pradesh by Singh et al. (2008). Sontakke et al. (2008), however, found no trends in this part of India since the 19th century but noted a dry epoch since 1968. It should be pointed out that their data set contained stations in the outer ranges only and not in, e.g., the Karakoram.

Further west in the Upper Indus Basin, at stations mainly in Pakistan, Archer and Fowler (2004) observed no trends in precipitation over the 20th century but a significant increase in winter, summer and annual precipitation at several stations starting in 1961. The increase was accompanied by increasing winter temperatures but decreasing summer temperatures (Fowler and Archer, 2006). Hartmann and Andresky (2013) found significant positive trends in precipitation in the Hindu Kush and the Sulaiman mountains for 1986-2010.

Satellite-based studies of trends in the present century (2000-2008/2001-2007) have documented a decrease in winter snow cover area in the Upper Indus (Immerzeel et al., 2009) but an increase in the Indus water volume stored in snow and ice (Immerzeel et al., 2010).

\subsection{Future projections of snowfall, temperature and precipitation}

In the last decades of the $21 \mathrm{st}$ century the temperature over India is projected to be on average $2.0-4.8^{\circ} \mathrm{C}$ higher than today, depending on the anthropogenic forcing scenario (Chaturvedi et al., 2012). In the Himalayas, a temperature increase of more than $7^{\circ} \mathrm{C}$ is seen with the strongest forcing, the Representative Concentration Pathway (RCP) 8.5
(Chaturvedi et al., 2012; Collins et al., 2013). Independently of precipitation changes, higher temperatures will decrease the fraction of precipitation falling as snow. Whether snowfall will increase or decrease thus depends on whether precipitation will increase enough to compensate for the reduced snow fraction.

Climate models from CMIP5, the most recent Coupled Model Inter-comparison Project (Taylor et al., 2011), project a general increase in precipitation over India, growing with anthropogenic forcing and with time, both annually (Chaturvedi et al., 2012) and during the summer monsoon (Menon et al., 2013). An increase was also seen in data from the previous model comparison project, CMIP3 (Turner and Annamalai, 2012). Menon et al. (2013) found that changes in the low-level winds suggest a northward shift in the monsoon by the end of the 21 st century for the strongest forcing scenario, although the total zonal strength of the monsoon remained fairly constant.

It should be emphasized that there is a large inter-model spread in precipitation projections. Guo et al. (2014) found that CMIP5 models with a more realistic representation of aerosols had a more negative impact on the monsoon than models that include only the direct effect of aerosols on radiation. Overall, the IPCC AR5 concludes that there is medium confidence in the increase in summer monsoon precipitation over South Asia (Christensen et al., 2013). Although precipitation projections are less reliable than temperature projections, agreement between models increases with time and anthropogenic forcing (Chaturvedi et al., 2012). Also, the CMIP5 multi-model mean has been considered to represent the monsoon and the actual climate in India better than any individual model (Chaturvedi et al., 2012; Sperber et al., 2013).

The IPCC AR5 has high confidence that the snow cover area in the Northern Hemisphere will be substantially reduced with anthropogenic forcing as in the strongest scenarios (Collins et al., 2013). For the range of RCPs2.6-8.5, CMIP5 models simulate $7-25 \%$ reductions in the spring snow cover extent by 2080-2100. For snowfall and snow water equivalents (SWE), the projections show more variation. While warming decreases the amount of snow, both through melting and through decreasing the snow fraction, more precipitation may increase snowfall in some of the coldest regions (Räisänen, 2008; Brutel-Vuilmet et al., 2013). Though shown to apply mainly to the northern parts of Eurasia and North America, there is a possibility that some of the higherlying terrain in the HKH may be similarly affected.

\subsection{Aims and scope}

For the $\mathrm{HKH}$, uncertainty in projections of future precipitation and snowfall comes on top of uncertainty in present time conditions. Observations are limited, especially in remote, high-elevation regions (Anders et al., 2006; Immerzeel, 2008; Tahir et al., 2011b; Winiger et al., 2005). Insufficient 
Table 1. Combinations of data types used in snowfall estimates: $T$ is temperature and $P$ is precipitation. $f(P, T)$ indicates that snowfall is calculated as a function of $P$ and $T$.

\begin{tabular}{lllll}
\hline & Precipitation & Temperature & Snowfall & Time \\
\hline MERRA & & & MERRA & Present \\
MERRA reference & MERRA & Terrain-adjusted MERRA & $f(P, T)$ & Present \\
MERRA T2m & MERRA & MERRA T2m & $f(P, T)$ & Present \\
Bias-corrected with obs. $T$ & MERRA & Bias-corr. terrain-adj. MERRA & $f(P, T)$ & Present \\
Bias-corrected with obs. $P$ & Bias-corr. MERRA & Terrain-adjusted MERRA & $f(P, T)$ & Present \\
Bias-corrected with obs. $T, P$ & Bias-corr. MERRA & Bias-corr. terrain-adj. MERRA & $f(P, T)$ & Present \\
CMIP5 $T$ & MERRA & Terrain-adj. MERRA + $T T$ & $f(P, T)$ & Future \\
CMIP5 $P$ & MERRA· $\Delta P$ & Terrain-adj. MERRA & $f(P, T)$ & Future \\
CMIP5 $T, P$ & MERRA· $P P$ & Terrain-adj. MERRA $+\Delta T$ & $f(P, T)$ & Future \\
Bias-corr. CMIP5 $T$ & Bias-corr. MERRA & Bias-corr. terrain-adj. MERRA $+\Delta T$ & $f(P, T)$ & Future \\
Bias-corr. CMIP5 $P$ & Bias-corr. MERRA $\cdot \Delta P$ & Bias-corr. terrain-adj. MERRA & $f(P, T)$ & Future \\
Bias-corr. CMIP5 $T, P$ & Bias-corr. MERRA $\cdot \Delta P$ & Bias-corr. terrain-adj. MERRA $+\Delta T$ & $f(P, T)$ & Future \\
\hline
\end{tabular}

Table 2. Data sets used in calculations of present-day snowfall.

\begin{tabular}{lcll}
\hline Product & Time & Hor. res. & Description \\
\hline MERRA & $1979-2012$ & $0.5^{\circ}$ lat, 0.7 long & Hourly atmospheric reanalysis data (Rienecker et al., 2011) \\
\hline APHRODITE V1204/V1101 & $1979-2007$ & $0.25^{\circ}$ & $\begin{array}{l}\text { Daily temperature and precipitation based on observations } \\
\text { (Yatagai et al., 2012; Yasutomi et al., 2011) }\end{array}$ \\
\hline CRU TS 3.20 & $1979-2011$ & $0.5^{\circ}$ & $\begin{array}{l}\text { Monthly temperature and precipitation based on observations } \\
\text { (Harris et al., 2014) }\end{array}$ \\
\hline TRMM 3B42 V7 & $1998-2012$ & $0.5^{\circ}$ & 3-hourly satellite-based precipitation (Huffman et al., 2007) \\
\hline GLOBE & & $1 \mathrm{~km}$ & Topography data set (Hastings and Dunbar, 1998) \\
\hline
\end{tabular}

knowledge of the amount of snow falling over the region today makes the contribution to both seasonal snowmelt and storage in glaciers correspondingly uncertain.

Recognizing this uncertainty, this study provides an ensemble of monthly mean snowfall estimates for all subbasins of the Indus, Ganges and Brahmaputra, today and for 2071-2100. For the present time estimates, we have combined MERRA reanalysis data (Rienecker et al., 2011) with observationally based data sets of precipitation and temperature: CRU TS (Harris et al., 2014), TRMM (Huffman et al., 2007) and APHRODITE (Yatagai et al., 2012; Yasutomi et al., 2011). Whereas Ménégoz et al. (2013) and Wiltshire (2014) analyzed Himalayan snowfall by downscaling reanalysis data with regional climate models, we have applied a simple terrain adjustment of the reanalysis temperature field.

The ensemble of present-day estimates is presented in Sect. 3. Future snowfall was then calculated based on the present-day snowfall and projected changes in temperature and precipitation in 14 and 15 CMIP5 models for the RCPs2.6 and 8.5, respectively. These results are presented in Sect. 4. The data and methods for both the present time and the future case are described in Sect. 2.
Three main features may be involved in precipitation changes in the HKH: changes in the summer monsoon, changes in western disturbances during winter and the general changes that occur in the thermodynamic properties of the air as the temperature increases and the air contains more water vapor. We have not considered the role of the different factors and only looked at how changes in temperature and precipitation affect snowfall. Unless otherwise specified, any reference to snow refers to precipitation falling as snow, not to the snow cover on the ground.

\section{Data and methods}

In addition to the original MERRA reanalysis snowfall, we estimated snowfall using different combinations of temperature and precipitation data. An overview of the combinations is shown in Table 1 and the data sets used presented in Tables 2 and 3 .

Present-day snowfall estimates were based on the following:

1. MERRA $2 \mathrm{~m}$ temperature adjusted to a higherresolution elevation grid and MERRA precipitation (Sect. 2.1). This was used as a basis for the other es- 
Table 3. CMIP5 models and RCPs used $(x)$ in calculations of 20712100 snowfall.

\begin{tabular}{lcc}
\hline Model & RCP2.6 & RCP8.5 \\
\hline CanESM2 & $\mathrm{x}$ & $\mathrm{x}$ \\
CCSM4 & $\mathrm{x}$ & $\mathrm{x}$ \\
CESM1-CAM5 & & $\mathrm{x}$ \\
CNRM-CM5 & & $\mathrm{x}$ \\
GFDL-CM3 & $\mathrm{x}$ & $\mathrm{x}$ \\
GFDL-ESM2G & $\mathrm{x}$ & \\
GISS-E2-R & $\mathrm{x}$ & $\mathrm{x}$ \\
HadGEM2-ES & $\mathrm{x}$ & $\mathrm{x}$ \\
IPSL-CM5A-LR & $\mathrm{x}$ & $\mathrm{x}$ \\
IPSL-CM5A-MR & $\mathrm{x}$ & $\mathrm{x}$ \\
MIROC-ESM & $\mathrm{x}$ & $\mathrm{x}$ \\
MIROC-ESM-CHEM & $\mathrm{x}$ & $\mathrm{x}$ \\
MIROC5 & $\mathrm{x}$ & $\mathrm{x}$ \\
MRI-CGCM3 & $\mathrm{x}$ & $\mathrm{x}$ \\
NorESM1-M & $\mathrm{x}$ & $\mathrm{x}$ \\
NorESM1-ME & $\mathrm{x}$ & $\mathrm{x}$ \\
\hline
\end{tabular}

timates and is referred to as MERRA reference snowfall. The adjusted temperature is referred to as terrainadjusted.

2. MERRA $2 \mathrm{~m}$ temperature and precipitation.

3. The MERRA data in (1), bias corrected with observation-based data for temperature and precipitation (Sect. 2.2).

Estimates for the last decades of the 21 st century were based on the following:

4. The MERRA data in (1) plus the changes in temperature and precipitation in a group of CMIP5 models over the coming century (Sect. 2.3).

5. Bias corrections with one of the data sets in (3) APHRODITE - plus the mean changes in temperature and precipitation in the CMIP5 models used in (4). This was done to account for the spread in the present-day estimates.

With the exception of original MERRA snowfall data, all snowfall estimates were based on the relationship between temperature and snowfall derived by Dai (2008). Based on observations, the conditional snow frequency over land was formulated as

$F\left(T_{\mathrm{s}}\right)=a\left[\tanh \left(b\left(T_{\mathrm{S}}-c\right)\right)-d\right]$,

where $T_{\mathrm{s}}$ is the surface air temperature $\left[{ }^{\circ} \mathrm{C}\right]$ and $a=-48.2292, b=0.7205, c=1.1662$ and $d=1.0223$. This may be interpreted as the probability, or fraction, of precipitation falling as snow at a given temperature. We calculated hourly snowfall as the product of $F$ and the amount of precipitation. Cutoffs for no rain and no snow were set at -10 and $10^{\circ} \mathrm{C}$, respectively, as this was the range of the data used by Dai (2008).

All snowfall estimates were made for the sub-basins defined in the HydroSHEDS data set (Lehner et al., 2008). The results were then aggregated to monthly sums for the Indus, Ganges and Brahmaputra basins.

Within each major basin, we also grouped the sub-basins into regions with similar characteristics of snow and precipitation. This was done with k-means clustering (MacQueen, 1967), using the square Euclidean distance as the distance measure. The seasonal cycles of precipitation, snow and snow fraction were first clustered separately, with the MERRA reference data and data bias corrected with CRU TS data as input. We then adjusted the clusters manually, prioritizing similarity of the relative seasonal cycles of snow and snow fraction and checking that both data sets gave similar results. Five groups were defined for the Indus and four for each of the other basins. This included a no-snow group in each basin.

\subsection{Reference present-day snowfall}

The horizontal resolution of the MERRA reanalysis data in the Himalayas is about $55 \mathrm{~km}$ latitude and $70 \mathrm{~km}$ longitude. To account for smaller-scale temperature variations in the rugged terrain, we used the vertical temperature gradient in MERRA to adjust the ground temperature to the GLOBE topography (Hastings and Dunbar, 1998). The elevationadjusted ground temperature was calculated as

$T_{\text {adj }}=T_{0}-\frac{\Delta T}{\Delta z} \Delta z_{0}=T_{0}-\frac{T_{2}-T_{1}}{z_{2}-z_{1}}\left(z_{\text {merra }, 0}-z_{\text {globe }}\right)$,

where $T_{0}$ is the MERRA $2 \mathrm{~m}$ temperature, $T_{1}$ is the temperature at the lowest pressure level above the ground, $T_{2}$ the temperature at the next pressure level and $z_{2}$ and $z_{1}$ the heights of these levels. $z_{\text {merra, } 0}$ and $z_{\text {globe }}$ are the elevations of the MERRA and GLOBE topography, respectively, and $\Delta z_{0}$ is the difference between them. The variables are illustrated in Fig. 2. The procedure combines the vertical temperature gradient in MERRA with the MERRA $2 \mathrm{~m}$ temperature and the elevation difference between MERRA and GLOBE. We have assumed that the most representative temperature gradient $(\Delta T / \Delta z)$ for this purpose is that of the MERRA layer nearest to, but not touching, the MERRA ground.

To reduce calculation time compared to using the original $1 \mathrm{~km}$ GLOBE resolution, both MERRA and GLOBE data were interpolated to a $4 \mathrm{~km}$ grid. Snowfall was calculated for each grid point and then aggregated for each sub-basin for each month.

Snowfall based on elevation-adjusted MERRA temperature and MERRA precipitation is used as a reference throughout this article. This is because the elevation-adjusted temperature and the $4 \mathrm{~km}$ grid were used as the starting point in all subsequent calculations. It does not mean that we con- 
a)

b)

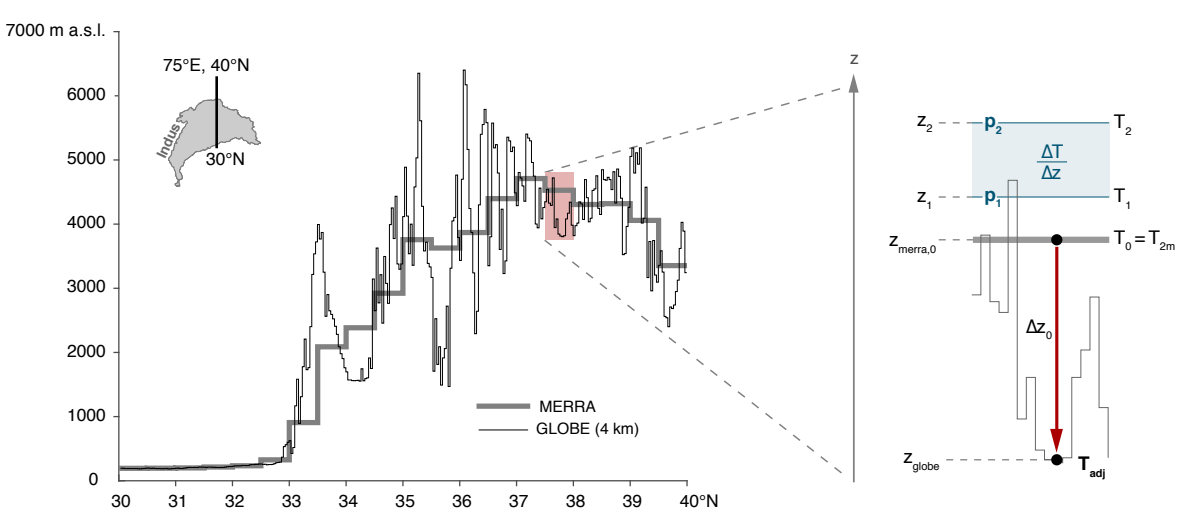

Figure 2. Procedure for elevation adjustment of MERRA temperature. (a) Comparison of MERRA and NOAA GLOBE (reduced to $4 \mathrm{~km}$ resolution) topography along $75^{\circ} \mathrm{E}$ from 30 to $40^{\circ} \mathrm{N}$. (b) Enlargement of the marked subsection in (a), demonstrating the variables in Eq. (2). $z_{\text {globe }}$ is the height of the topography in GLOBE, $z_{\text {merra, } 0}$ that of MERRA and $\Delta z_{0}$ the difference between the two. $z_{1}$ is the height of the MERRA pressure level that is closest to the ground, and $z_{2}$ is the height of the next pressure level above this. $T_{0}$ is the $2 \mathrm{~m}$ temperature in MERRA and $T_{\text {adj }}$ the final adjusted temperature. $\Delta T / \Delta z$ is the vertical temperature gradient in the layer between $z_{1}$ and $z_{2}$. This is combined with $\Delta z_{0}$ to adjust the MERRA temperature $\left(T_{0}\right)$ from the MERRA elevation to the NOAA GLOBE elevation $\left(T_{\text {adj }}\right)$.

sider these snowfall values to be closer to the truth than any of the other estimates.

\subsection{Bias-corrected present-day snowfall}

A second group of present-day snowfall estimates was made from MERRA precipitation and elevation-adjusted temperature bias corrected with observationally based data sets: APHRODITE daily temperature and precipitation for 19792007, CRU TS monthly temperature and precipitation for 1979-2011 and TRMM 3B42 3-hourly precipitation for 1998-2012. Bias corrections were performed on daily or monthly scales, depending on the input data, and the result distributed over the hourly time steps of the MERRA temperature and precipitation. As a result, the diurnal cycle in MERRA is maintained in all estimates. Snowfall was then calculated following the same procedure as for the MERRA reference snowfall (Sect. 2.1). When referring to APHRODITE snow or CRU snow anywhere in this article, this is the snowfall calculated using MERRA precipitation and temperature, both bias corrected with these data sets.

Temperature data are generally assumed to be normally distributed, and as described in Teutschbein and Seibert (2012) and references therein the data can be bias corrected through a Gaussian distribution mapping. We thus bias corrected the elevation-adjusted MERRA temperature with the observationally based APHRODITE V1204 daily temperature by mapping the distribution of the MERRA data to the Gaussian distribution of the observations.

As the CRU TS 3.20 includes monthly mean daily minimum and maximum temperatures, the method described by
Wang and Zeng (2013) was used. Bias-corrected daily maximum temperatures were defined as

$T_{\mathrm{d}, \text { max }}=T_{\text {merra,d,max }}-\left(T_{\text {merra,mn,max }}-T_{\text {cru,mn,max }}\right)$,

where "d" denotes daily and "mn" monthly. Daily minimum temperatures were then corrected by adjusting the diurnal range

$T_{\mathrm{d}, \text { min }}=T_{\mathrm{d}, \max }-\Delta T_{\text {merra, }} \cdot \frac{\Delta T_{\text {cru,mn }}}{\Delta T_{\text {merra,mn }}}$,

where $\Delta T$ represents the diurnal and monthly temperature range.

The distribution mapping procedure described by Ines and Hansen (2006) was used to bias correct MERRA precipitation with APHRODITE V1101R2 daily precipitation and daily accumulated TRMM 3B42 3-hourly precipitation. This is a two-step procedure involving frequency and intensity adjustments. We defined precipitation days as days with at least $0.1 \mathrm{~mm}$ in the observations. The frequency was first adjusted by setting the number of precipitation days in MERRA equal to that of the observations. This was done by removing the lowest daily values. The intensity was then adjusted by fitting the remaining days to the gamma distribution of the observations.

Bias corrections with CRU TS 3.20 monthly precipitation were done with a simple correction factor to adjust the monthly MERRA total to that of CRU (e.g., Ines and Hansen, 2006).

\subsection{Projected snowfall}

The MERRA reanalysis was also the basis for estimates of future snowfall. The changes in temperature and precipita- 


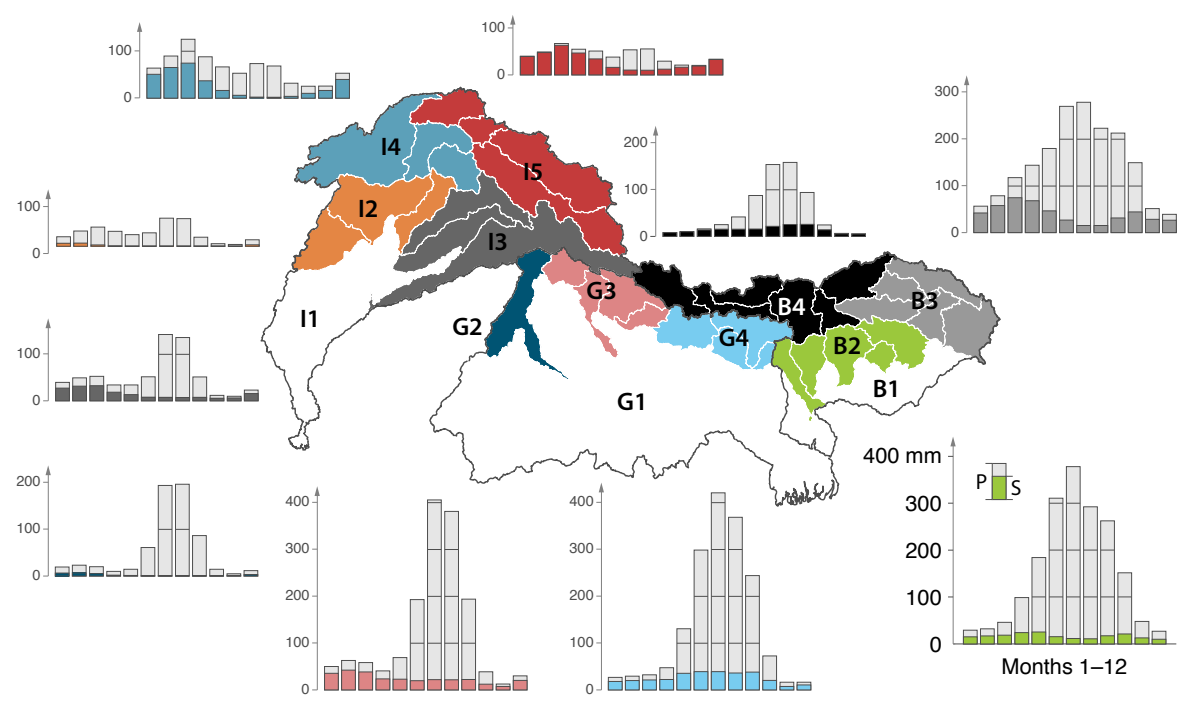

Figure 3. Monthly mean MERRA precipitation and MERRA reference snowfall in sub-basin clusters of the Indus (I), Ganges (G) and Brahmaputra (B). Total bar height: MERRA precipitation $(P)(\mathrm{mm})$. Colored bars: snowfall $(S)(\mathrm{mm} S W E)$ based on MERRA precipitation and terrain-adjusted MERRA temperature, in the region with the same color. Cluster 1 in each basin is considered snow free, and the seasonal cycles are not shown. All subplots have the same scale.

tion from 1971-2000 to 2071-2100 were added to the reanalysis data and snowfall calculated following the same procedure as for the present time. Climate change input came from models that were part of the Coupled Model Intercomparison Project 5 (CMIP5; Taylor et al., 2011), for the Representative Concentration Pathways (RCP) 2.6 and 8.5 (Moss et al., 2010; van Vuuren et al., 2011). The models used are listed in Table 3.

Due to the different spatial resolution of the models, changes were defined as monthly mean changes on the sub-basin level. For temperature, the absolute change was used and for precipitation the fractional change. Future projected snowfall was calculated with reference to elevationadjusted MERRA snowfall for each model. Due to large deviations in estimates of present-day snowfall (Sect. 3), we also calculated snowfall for the CMIP5 multi-model mean changes with reference to the lowest present time estimate, APHRODITE snowfall.

\subsection{The rain-snow line}

Not all temperature changes affect snowfall. We defined the rain-snow line as the elevation where the temperature suggests a shift from rain to snow. Technically, this is a conditional rain-snow line, as no precipitation was required. For every hour, all grid cells that had a snow fraction/probability between 0.25 and 0.75 , corresponding to a temperature between 0.9 and $1.3^{\circ} \mathrm{C}$, were identified. The monthly rainsnow line was then set as the mean elevation of these grid cells and time steps. For present-day conditions this was done using elevation-adjusted MERRA temperature and with temperature bias-corrected with APHRODITE. Projected tem- perature changes in the CMIP5 RCP8.5 were then added to these temperatures and the procedure repeated.

\section{Present-day snowfall}

\subsection{Seasonal cycles of precipitation and snowfall}

Figure 3 gives an overview of the seasonal cycle of rain and snow in different parts of the HKH based on MERRA precipitation and MERRA reference snowfall (Sect. 2.1). The upper Indus basin gets more snow than rain; in other subbasins of the Indus, Ganges and Brahmaputra, rainfall dominates. This difference is caused by different precipitation cycles, as well as elevation differences. Whereas the summer monsoon dominates in the central Himalayas, winter depressions bring most of the precipitation in the upper Indus - at a time when low temperatures mean that precipitation falls as snow in larger areas than it would in summer. Although snow fractions are lower in the upper Brahmaputra, monsoon precipitation produces a substantial amount of summer snow at high elevations.

In the northwesternmost cluster in the Indus, I4, March is the wettest month and also the month with the highest total amount of snowfall. Precipitation has a second peak during July and August, but the temperature is then too high to allow much snowfall. Further east, in cluster I5, more terrain at higher elevations cause higher snow fractions during summer, but winter and spring are still the dominant snow seasons. The summer peak in precipitation in this cluster is caused by the two eastern sub-basins. There is little summer precipitation in the west. 

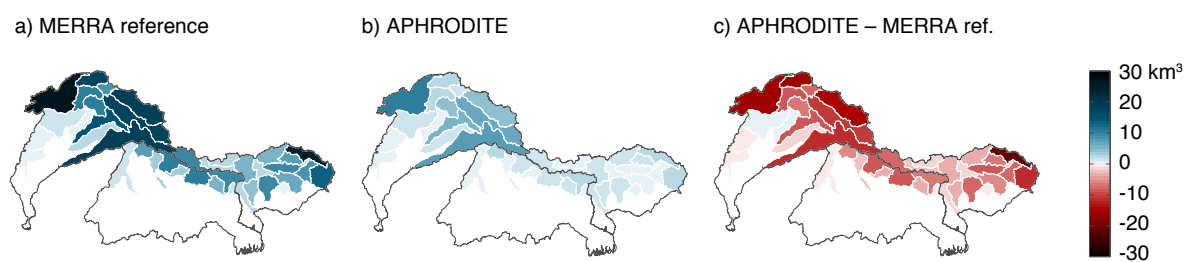

Figure 4. The effect of bias corrections with APHRODITE temperature and precipitation: (a) MERRA reference snowfall, (b) snowfall based on bias corrections with APHRODITE, (c) APHRODITE (b) minus MERRA reference snowfall (a).

In Brahmaputra's cluster B4 and Ganges' G4, maximum snowfall occurs during the summer monsoon. Higher temperatures during summer mean that the snow fraction is lower than in winter, but as there is much more summer precipitation, the amount of snow is also higher. Rare occurrences of precipitation during the cold winter, together with the combination of snowfall and snowmelt during summer, make the seasonal cycle of snow depth in the central Himalayas unpronounced (Ménégoz et al., 2013). In the upperlevel basins in Brahmaputra's B3, the summer is also the main precipitation season, but the peak is less sharp than further west. As a result, snowfall is at a maximum in MarchApril.

\subsection{Comparison of snowfall estimates}

The MERRA reference snowfall described in Sect. 3.1 differs greatly from snowfall based on bias-corrected temperature and precipitation. Large differences between temperature and precipitation data sets for the $\mathrm{HKH}$ cause corresponding deviations in snowfall - not only between MERRA-based estimates and bias-corrected data but also among estimates based on bias corrections with different data sets. This can be seen from Table 4, which displays annual snowfall estimates for combinations of the bias corrections described in Sect. 2.2, aggregated to the major basins. Data for the individual sub-basins are included as a Supplement.

With the exception of snowfall based on MERRA precipitation and MERRA temperature bias corrected with CRU TS in the Ganges basin, all estimates based on bias-corrected data are lower than the MERRA reference snowfall. The lowest estimates are those based on bias corrections with APHRODITE precipitation and temperature. This combination produced only $33 \%$ of the reference snowfall in the Indus Basin, $22 \%$ in the Ganges basins and $17 \%$ in the Brahmaputra Basin. While the difference is large in all subbasins that have snow today, it is especially large in the upper parts of the Indus and Brahmaputra basins (Fig. 4). In comparison, bias corrections with CRU TS temperature and precipitation produce $54 \%$ of the reference snowfall in the Indus, $75 \%$ in the Ganges and $42 \%$ in the Brahmaputra factors of 2-4 compared to APHRODITE. It should be noted that, as the time periods covered by the data sets are not equal, the results are not strictly comparable, but tests us- ing different MERRA periods (not shown) indicate that there would be no major difference in the monthly means.

The MERRA reference snowfall deviates about $10 \%$ from the original MERRA reanalysis snowfall: negatively in the Indus and Brahmaputra and positively in the Ganges. Two effects contribute to this: the use of elevation-adjusted temperature and the use of the function from Dai (2008) when relating precipitation type to temperature. The effect of the function may be seen from the "MERRA T2m" in Table 4. For this variable, the Dai function was applied directly to the MERRA 2 m temperature, i.e., without the elevation adjustment. Comparing this with the original MERRA reanalysis snowfall ("MERRA") indicates that the Dai function acts to reduce the snow fraction. The elevation adjustment of temperature depends on the MERRA vertical temperature gradient as well as the topography of MERRA and GLOBE. GLOBE is the result of merging various other elevation data, and the quality in each region depends on the available input data. Globally, half of the data points have been estimated to have a vertical accuracy of less than $30 \mathrm{~m}$, whereas some points in Antarctica may be as much as $300 \mathrm{~m}$ off (Hastings and Dunbar, 1998, 1999). The effect of elevation adjusting the temperature or of using the Dai function amounts to changes on the order of 5-20\%. This is much less than the effect of bias corrections with observation-based data.

The large difference between MERRA reference snowfall and snowfall based on bias-corrected data results from differences in both temperature and precipitation, but differences in the precipitation pattern have the greatest effect. Estimates for which only the precipitation has been bias corrected are lower than those where only the temperature has been bias corrected (Table 4). This is not solely an effect of more precipitation in MERRA than in the observation-based data, although MERRA is wetter than all the data sets in the Indus, as well as wetter than APHRODITE in the Ganges and the Brahmaputra. An inland and upward shift in the MERRA precipitation adds to the differences. As shown in Fig. 5, all the observation-based precipitation data sets are wetter than MERRA in most of the lowlands and in the foothills of the HKH but drier in the higher-elevation regions further inland. In MERRA, the precipitation belt is shifted higher up in the Himalayas, where temperatures are lower and more of the precipitation falls as snow. 
Table 4. Annual snowfall estimates for the Indus, Ganges and Brahmaputra basins. $S$ is snow $\left(\mathrm{km}^{3} \mathrm{SWE}\right) . P$ is precipitation $\left(\mathrm{km}{ }^{3}\right) . \% S$ and $\% P$ are percent of MERRA reference snowfall and MERRA precipitation. First horizontal section has no bias corrections. Second, third and fourth section have bias corrections with $T, P$ and both $T$ and $P$.

\begin{tabular}{|c|c|c|c|c|c|c|c|c|c|c|c|c|}
\hline \multirow[b]{2}{*}{ Input } & \multicolumn{4}{|c|}{ Indus Basin } & \multicolumn{4}{|c|}{ Ganges Basin } & \multicolumn{4}{|c|}{ Brahmaputra Basin } \\
\hline & $S$ & $\% S$ & $P$ & $\% P$ & $S$ & $\% S$ & $P$ & $\% P$ & $S$ & $\% S$ & $P$ & $\% P$ \\
\hline MERRA reference & 148 & 100 & 422 & 100 & 54 & 100 & 1147 & 100 & 119 & 100 & 733 & 100 \\
\hline MERRA & 166 & 112 & 422 & 100 & 49 & 90 & 1147 & 100 & 129 & 109 & 733 & 100 \\
\hline MERRA T2m & 154 & 104 & 422 & 100 & 42 & 77 & 1147 & 100 & 109 & 92 & 733 & 100 \\
\hline$T$ APHRODITE & 113 & 76 & 422 & 100 & 30 & 55 & 1147 & 100 & 74 & 62 & 733 & 100 \\
\hline$T$ CRU & 126 & 85 & 422 & 100 & 81 & 151 & 1147 & 100 & 109 & 92 & 733 & 100 \\
\hline$P$ APHRODITE & 66 & 44 & 315 & 75 & 22 & 42 & 1020 & 89 & 35 & 30 & 567 & 77 \\
\hline$P$ TRMM & 72 & 49 & 404 & 96 & 31 & 57 & 1244 & 108 & 63 & 54 & 835 & 114 \\
\hline$P$ CRU & 84 & 56 & 398 & 94 & 30 & 56 & 1100 & 96 & 53 & 45 & 716 & 98 \\
\hline$P, T$ APHRODITE & 49 & 33 & 315 & 75 & 12 & 22 & 1020 & 89 & 20 & 17 & 567 & 77 \\
\hline$P$ APHRODITE, $T$ CRU & 62 & 42 & 315 & 75 & 34 & 63 & 1020 & 89 & 33 & 28 & 567 & 77 \\
\hline$P$ TRMM, $T$ APHRODITE & 54 & 36 & 390 & 92 & 18 & 34 & 1195 & 104 & 39 & 33 & 815 & 111 \\
\hline$P$ TRMM, $T$ CRU & 65 & 44 & 403 & 96 & 46 & 85 & 1254 & 109 & 58 & 49 & 813 & 111 \\
\hline$P$ CRU, $T$ APHRODITE & 65 & 44 & 395 & 94 & 17 & 31 & 1106 & 96 & 31 & 26 & 718 & 98 \\
\hline$P, T$ CRU & 80 & 54 & 398 & 94 & 41 & 75 & 1100 & 96 & 49 & 42 & 716 & 98 \\
\hline
\end{tabular}

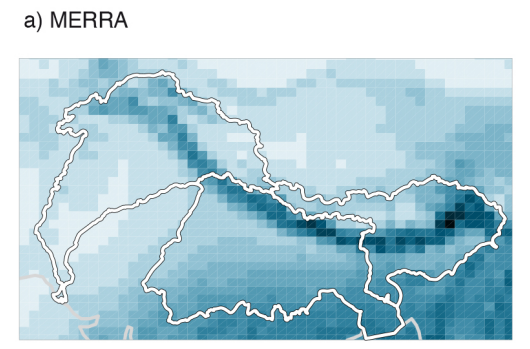

b) APHRODITE
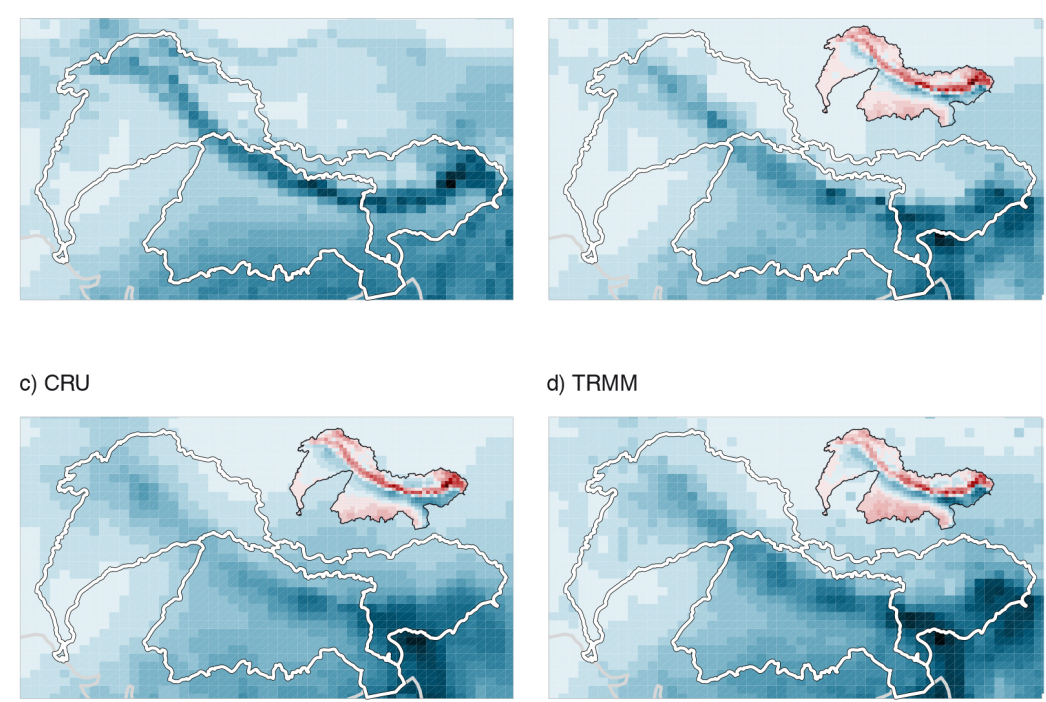

d) TRMM

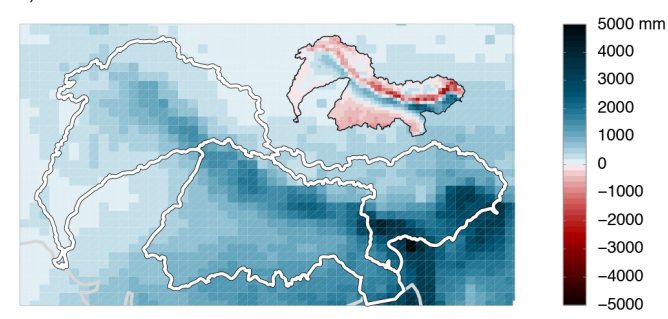

Figure 5. Difference between MERRA precipitation and observation-based data. (a) Annual mean MERRA precipitation. (b, c, d) Annual mean MERRA precipitation bias corrected with observations: APHRODITE, CRU TS and TRMM 3B42. For each data set, the small inset maps show the observations minus MERRA.

In addition, $\mathrm{HKH}$ temperatures are lower in MERRA than in APHRODITE and in the upper Indus also than in CRU TS (Fig. 6). The lower temperatures in MERRA cause higher snow fractions, further increasing the difference between the MERRA reference snowfall and APHRODITE snowfall. Oppositely, CRU TS is colder than MERRA throughout the Ganges, leading to higher snowfall estimates when bias correcting MERRA temperatures with CRU TS (Table 4).

We do not see any reason to consider either the observation-based data sets or the reanalysis as the ground truth. The reanalysis has the benefit of being physically consistent, though precipitation is a pure model product. In the other data sets, the number of observations vary greatly within the region.

The lack of observations in the HKH has been pointed out in many studies. Most meteorological stations are located in the valleys and do not necessarily represent weather conditions in higher terrain. As demonstrated by Palazzi et al. (2013), station-based data sets like APHRODITE and CRU TS are merely mathematical interpolations in ma- 
a) MERRA

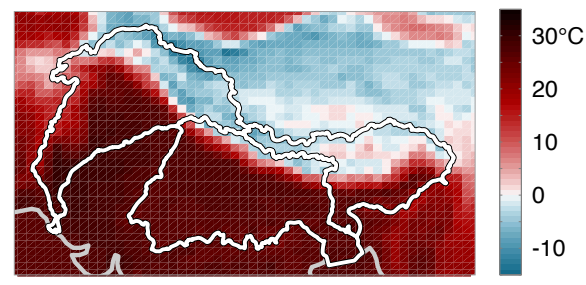

b) APHRODITE - MERRA

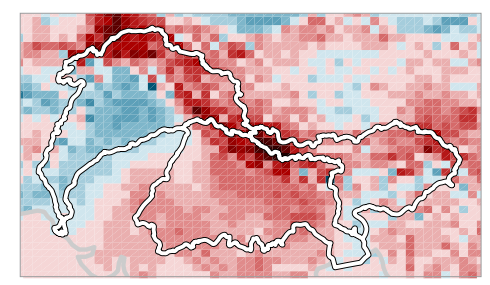

c) CRU - MERRA

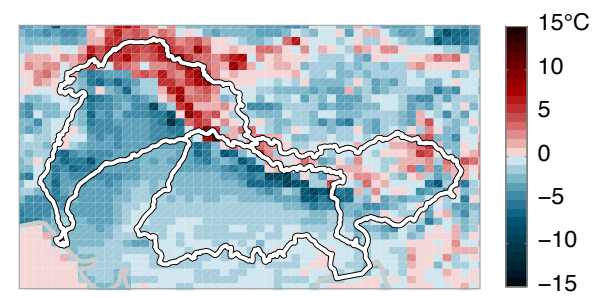

Figure 6. Difference between MERRA temperature and observation-based data. (a) Annual mean MERRA temperature. (b, c) Annual mean MERRA temperature bias corrected with observations: APHRODITE and CRU TS.

jor parts of the HKH and on the Tibetan Plateau. Immerzeel (2008) showed that the number of observations going into version 2.1 of the CRU data set in the Himalayan region varies greatly. A drop in the mid-1990s suggests that caution should be taken when interpreting data at later times. Maps (not shown) of station coverage in version 3.20, used in this study, show that this problem persists.

The fact that more of the precipitation falls as snow at higher elevations may itself lead to an underestimation of precipitation in the mountains. In addition to the lack of observations in high terrain, gauges tend to capture snow less easily than rain, leading to a possible under-registration of precipitation at the few high-elevation stations that exist. Comparing stations along a vertical profile in the Karakoram, Winiger et al. (2005) found that precipitation multiplied by a factor of 5-10 from 2500 to 5000-6000 m a.s.l. This maximum is much higher than reported in most other studies, and they attributed this to the valley dominance of stations normally used.

Indications of too little precipitation at higher elevations were also given by Tahir et al. (2011b), as APHRODITE precipitation was too low to account for the observed discharge in the Hunza river in the Karakoram. Anders et al. (2006) reported that TRMM radar data underestimated precipitation at higher elevations in the Himalayas due to the low ability of the radar to detect very low precipitation and low-moderate snowfall rates. However, Krakauer et al. (2013) found that both TRMM and APHRODITE had too much precipitation compared to observations from the few existing stations at elevations above $3000 \mathrm{~m}$ a.s.l. in Nepal.

Satellite data are a promising future alternative for measuring snowfall but presently of limited use. MODIS and LANDSAT satellite data have been used in several studies of snow and ice in the Himalayas (Tahir et al., 2011a, b; Bookhagen and Burbank, 2010; Hewitt, 2005; Krishna, 2005; Negi et al., 2009; Jain et al., 2009; Butt, 2012; Gao et al., 2012; Kulkarni et al., 2010; Immerzeel et al., 2009), but these data contain only snow cover area with no measure of the snow thickness or snow water equivalents. The NASA AMSR-E SWE data set distributed by the National Snow and Ice Data Center could have been used, but correla- tions between AMSR-E SWE and ground observations have been shown to be poor (Tedesco and Narvekar, 2010; Byun and Choi, 2014; Kumar et al., 2006). As AMSR-E SWE has been found to underestimate snow depth, we concluded that incorporating these data into our ensemble would not likely constrain the results or add new information.

Defining snowfall based on MERRA precipitation and elevation-adjusted temperature as a reference was done mainly to have a single reference when comparing the data sets against each other. Also, we believe the elevation adjustment of temperature represents an enhancement compared to the original MERRA reanalysis. MERRA was chosen mainly because it has an hourly resolution, allowing diurnal temperature variations to affect snowfall. However, even though this estimate is much higher than all the bias-corrected estimates, it cannot be discarded. It has been argued that reanalysis data and regional climate models may in some cases be as good as, or better, than observations in the HKH (Wiltshire, 2014; Ménégoz et al., 2013; Akhtar et al., 2008). Akhtar et al. (2008) got better results when modeling river discharge in three upper Indus catchments with an RCM-based hydrological model than with one based on the few observations available within the region. They concluded that it was preferable to use RCM data directly as input to hydrological models in this region.

As shown in the small inset maps in Fig. 5, MERRA precipitation is higher than observed precipitation throughout the HKH, and the same has previously been shown for ERA-Interim reanalysis precipitation (Palazzi et al., 2013). In MERRA, the precipitation belt is shifted upward in the terrain compared to in the observation-based data sets. Whether this shift is realistic cannot be determined as long as observations from upper-level terrain are either missing or likely too low.

\section{Projected future snowfall}

Whether higher temperatures lead to less snowfall depends on whether the temperature changes from below to above freezing and whether this change occurs at a time when there is precipitation. The maps in Fig. 7 illustrate where a temper- 
a)

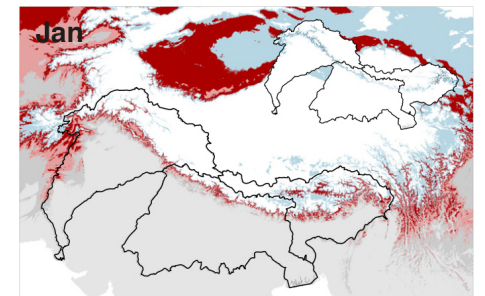

c)

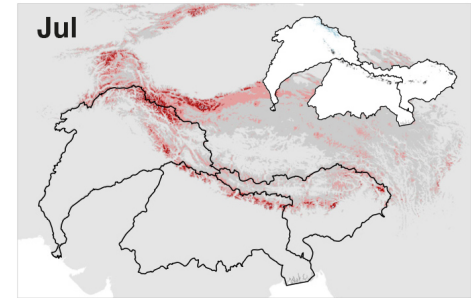

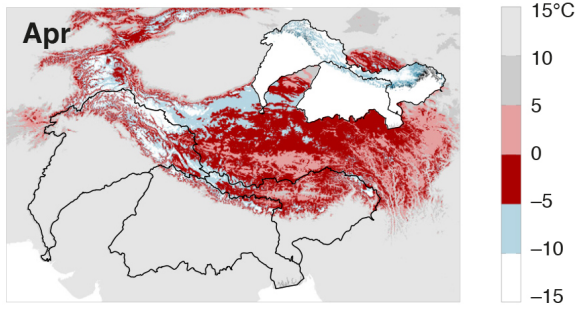

d)

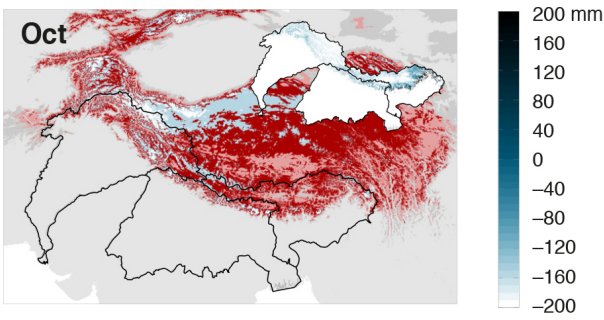

Figure 7. Regions where increasing temperatures are likely to cause a shift from snow to rain. Data are monthly mean MERRA temperature, terrain adjusted to a $4 \mathrm{~km}$ GLOBE grid. Red indicates temperature between -5 and $0^{\circ}$ considered critical. Small inset maps show monthly MERRA precipitation in the critical zones.

ature increase is most likely to affect snowfall and snowmelt. In the red zones, where the monthly temperature today is between -5 and $0^{\circ} \mathrm{C}$, the projected temperature increase of $2-7^{\circ} \mathrm{C}$ (Chaturvedi et al., 2012; Collins et al., 2013; Wiltshire, 2014) may be considered critical. Such a change would change snowfall to rain and also cause a change from freezing to melting of snow and ice. The pink zones, with monthly mean temperatures of $0-5^{\circ} \mathrm{C}$, would similarly change from a climate where precipitation may often fall as snow to one that is snow free.

In January (Fig. 7a) only the lower parts of the Himalayas are affected, as most of the region would still have temperatures well below the freezing point. The small inset map shows precipitation in the red zone; a narrow band along the range. Oppositely, in July (Fig. 7c) the temperature is already above $5{ }^{\circ} \mathrm{C}$ in most of the region, though at higher elevations along the Himalayan range and in the Karakoram the change can be critical. The most widespread changes are seen in spring and fall. In April and October (Fig. 7b and d), large areas in the HKH and on the Tibetan Plateau risk a change from below to above freezing.

Incorporating CMIP5 precipitation changes, we find that the projected temperature increase has a larger impact so that snowfall will be reduced in the Indus, Ganges and Brahmaputra basins by 2071-2100 compared to today. Details for the major basins are presented in Sect. 4.1. How much increased temperatures reduce snowfall within a region depends on the location of the rain/snow line today compared to the terrain distribution. Results for selected upper-level sub-basins in the Indus and Brahmaputra will be discussed in that context in Sect. 4.2.

The large deviations in the estimates of present-day snowfall (Sect. 3) mean that there will be correspondingly large deviations in projected values. To account for this, most results are shown with reference to the highest and lowest present-day estimates: MERRA reference snowfall and to APHRODITE-based snowfall. Future estimates relative to CRU and TRMM are assumed to lie between those of MERRA and APHRODITE.

\subsection{Basin-scale projections}

In the Indus, Ganges and Brahmaputra basins, the CMIP5 models project a mean increase in both temperature (Fig. 8) and precipitation (Fig. 9) in the region by 2071-2100 for both RCPs 2.6 and 8.5. The RCP8.5 multi-model mean change in temperature varies through the year, with a $4.9-6.2^{\circ} \mathrm{C}$ increase in the Indus, $3.6-5.2^{\circ} \mathrm{C}$ in the Ganges and $4.2-6.0^{\circ} \mathrm{C}$ in the Brahmaputra. The increase is smallest during the summer months. The dip in the summer is also seen, though less pronounced, with the RCP2.6. The summer is also the season with the largest absolute increase in precipitation.

Compared to present-day estimates, the CMIP5 models project less snowfall in the Indus, Ganges and Brahmaputra basins in the last decades of this century. This can be seen from Fig. 10. The projected multi-model mean is lower than today in all calendar months for both RCPs2.6 and 8.5. With the RCP2.6, some models suggest an increase in some months, mainly in winter and spring. This is also the case for one or two models with the RCP8.5, whereas other models indicate that the snowfall in the same months will be only half of today's values.

In the Ganges Basin (Fig. 10b) the seasonal distribution of snowfall today is mainly flat, with equal amounts of snowfall from January through September. Reductions in summer snowfall with the RCP8.5 would change the seasonal cycle into a winter-dominated one. To a lesser degree, this 
a) Indus

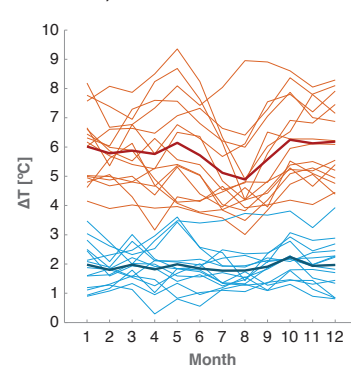

b) Ganges

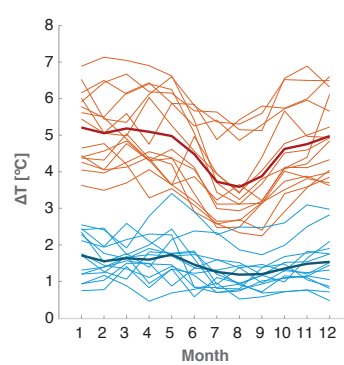

c) Brahmaputra

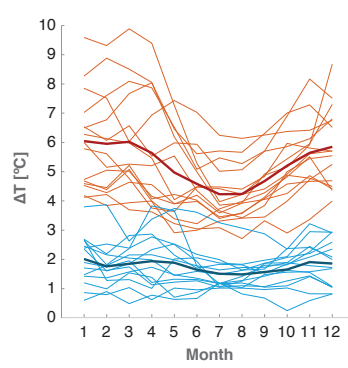

- RCP 8.5

RCP 8.5 mean

RCP 2.6

RCP 2.6 mean

Figure 8. Projected future temperature change from 1971-2000 to 2071-2100 in the (a) Indus, (b) Ganges and (c) Brahmaputra basins. Thin lines show the individual CMIP5 models, while stronger lines show the multi-model mean.

a) Indus

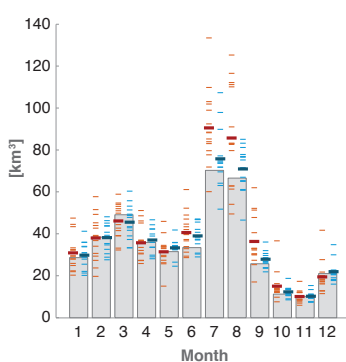

b) Ganges

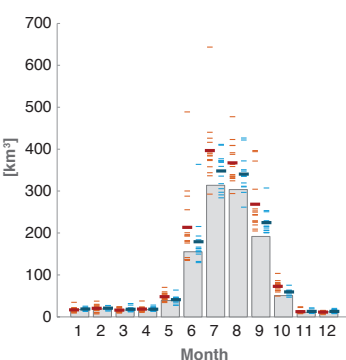

c) Brahmaputra

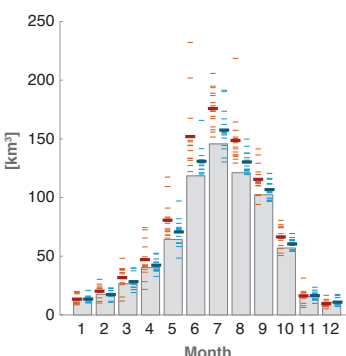

1979-2008:

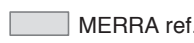

2071-2100:

RCP 8.5

RCP 8.5 mean

RCP 2.6

RCP 2.6 mean

Figure 9. Projected future precipitation in the (a) Indus, (b) Ganges and (c) Brahmaputra basins. Gray bars indicate MERRA 1979-2008. Thin lines and horizontal marks on the bars show the individual CMIP5 models and the multi-model mean for 2071-2100.

a) Indus

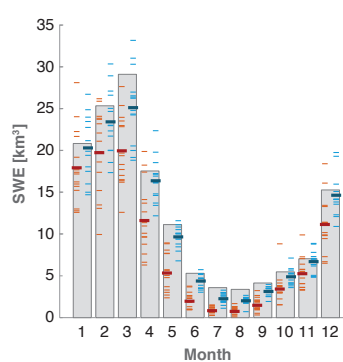

b) Ganges

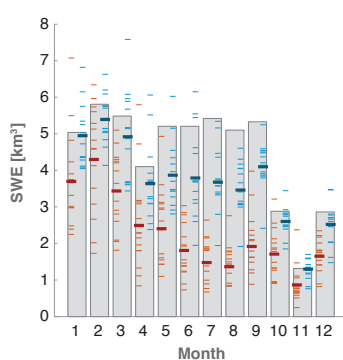

c) Brahmaputra

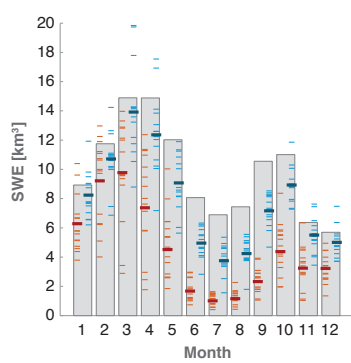

1979-2008:

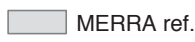

2071-2100:

RCP 8.5

RCP 8.5 mean

- RCP 2.6

RCP 2.6 mean

Figure 10. Projected future snowfall in the (a) Indus, (b) Ganges and (c) Brahmaputra basins, with reference to MERRA reference snowfall. Gray bars indicate MERRA reference snowfall for 1979-2008. Thin lines and horizontal marks on the bars show the individual CMIP5 models and the multi-model mean for 2071-2100 based on changes in temperature and precipitation, as described in Sect. 2.3 .

is also the case for RCP2.6. As summer precipitation is projected to increase in all of the Ganges (not shown, but consistent with Menon et al., 2013), this indicates that large areas are at elevations where a small increase in the summer temperature may cause a shift from snow to rain. This is seen as the red band along the upper Ganges in Fig. 7c. Reductions in summer snowfall are also large in the Brahmaputra (Fig. 10b), whereas in the Indus the largest total changes occur in March-May (Fig. 10a).

As the MERRA reference snowfall for today is much larger than APHRODITE snowfall (Sect. 3.2), projected absolute changes for 2071-2100 are also much larger in
MERRA. The relative changes are more similar, though larger with reference to APHRODITE. Annual snowfall changes for each major basin are presented in Table 5 for changes in temperature, precipitation or both and with reference to MERRA and Aphrodite present-day snowfall. Changes at the sub-basin level are shown in Fig. 11. In the Ganges Basin, both MERRA- and APHRODITE-based multi-model mean snowfall is reduced by about $20 \%$ with the RCP2.6 and 50\% with the RCP8.5. In the Indus and Brahmaputra basins, the differences between MERRA- and APHRODITE-based changes are larger but not as large as for the absolute values. With reference to MERRA and 
Table 5. Projected change in annual snowfall from 1971-2000 to 2071-2100, with reference to terrain-adjusted MERRA and APHRODITE. $\Delta S_{\text {abs }}\left(\mathrm{km}^{3}\right)$ is the absolute change, and $\Delta S_{\text {rel }}(\%)$ is the relative change compared to the present-day MERRA reference snowfall. Values are presented with the CMIP5 multi-model mean as the main value and the span of individual models in brackets (MERRA only). $\Delta T P$ indicates that changes in both temperature and precipitation are included, whereas $\Delta P$ and $\Delta T$ denotes changes only in precipitation or temperature, respectively.

\begin{tabular}{|c|c|c|c|c|c|c|c|}
\hline & \multicolumn{2}{|c|}{ Indus } & \multicolumn{2}{|c|}{ Ganges } & \multicolumn{2}{|c|}{ Brahmaputra } \\
\hline & & $\Delta S_{\text {abs }}\left(\mathrm{km}^{3}\right)$ & $\Delta S_{\text {rel }}(\%)$ & $\Delta S_{\text {abs }}\left(\mathrm{km}^{3}\right)$ & $\Delta S_{\text {rel }}(\%)$ & $\Delta S_{\text {abs }}\left(\mathrm{km}^{3}\right)$ & $\Delta S_{\text {rel }}(\%)$ \\
\hline \multirow{6}{*}{ RCP8.5 } & MERRA, $\triangle T P$ & $-49[-83 /-9]$ & $-33[-56 /-6]$ & $-27[-36 /-14]$ & $-50[-66 /-25]$ & $-64[-93 /-39]$ & $-54[-79 /-33]$ \\
\hline & MERRA, $\Delta T$ & $-51[-67 /-34]$ & $-34[-45 /-23]$ & $-28[-34 /-21]$ & $-51[-64 /-39]$ & $-71[-87 /-53]$ & $-60[-73 /-44]$ \\
\hline & MERRA, $\Delta P$ & $5[-25 / 44]$ & $4[-17 / 30]$ & $7[-4 / 17]$ & $12[-7 / 31]$ & $20[-17 / 50]$ & $17[-15 / 42]$ \\
\hline & APHRO, $\triangle T P$ & -25 & -51 & -7 & -56 & -13 & -67 \\
\hline & $\mathrm{APHRO}, \Delta T$ & -25 & -52 & -7 & -57 & -14 & -71 \\
\hline & APHRO, $\Delta P$ & 1 & 1 & 1 & 6 & 3 & 16 \\
\hline \multirow{6}{*}{$\mathrm{RCP} 2.6$} & MERRA, $\triangle T P$ & $-15[-40 / 6]$ & $-10[-27 / 4]$ & $-10[-19 /-3]$ & $-18[-36 /-5]$ & $-25[-42 /-5]$ & $-21[-35 /-4]$ \\
\hline & MERRA, $\Delta T$ & $-18[-27 /-9]$ & $-12[-18 /-6]$ & $-12[-21 /-6]$ & $-21[-39 /-11]$ & $-29[-47 /-13]$ & $-25[-40 /-11]$ \\
\hline & MERRA, $\Delta P$ & $3[-18 / 25]$ & $2[-12 / 17]$ & $3[-2 / 10]$ & $5[-4 / 19]$ & $7[-8 / 28]$ & $6[-6 / 23]$ \\
\hline & $\mathrm{APHRO}, \Delta T P$ & -9 & -18 & -2 & -20 & -6 & -29 \\
\hline & APHRO, $\Delta T$ & -10 & -19 & -3 & -23 & -6 & -32 \\
\hline & APHRO, $\Delta P$ & 1 & 1 & 0 & 4 & 1 & 6 \\
\hline
\end{tabular}

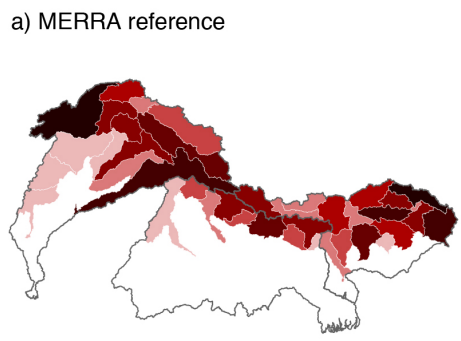

b) APHRODITE

c) MERRA reference

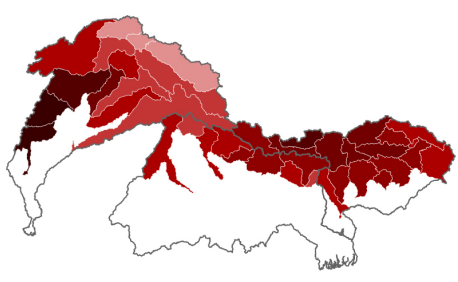

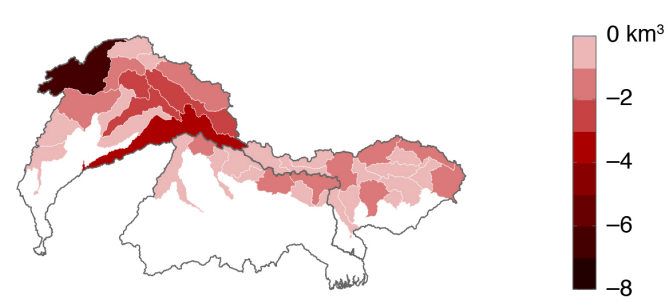

d) APHRODITE

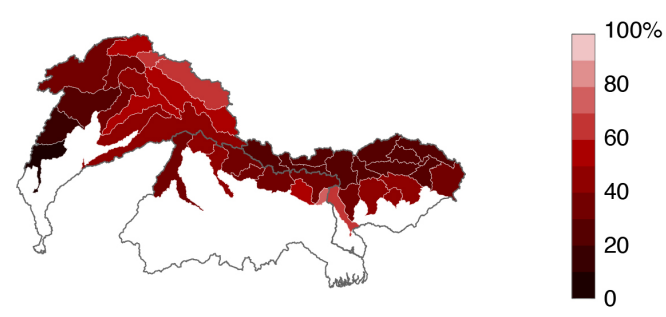

Figure 11. Projected future changes in snowfall in sub-basins of the Indus, Ganges and Brahmaputra basins. (a) Absolute change $\left(\mathrm{km}^{3}\right)$ with reference to MERRA reference snowfall. (b) Absolute change $\left(\mathrm{km}^{3}\right)$ with reference to APHRODITE snowfall. (c, d) Corresponding relative changes $(\%)$ with reference to MERRA and APHRODITE.

APHRODITE, respectively, the reduction in snowfall in the Indus Basin is 30 and $50 \%$ with the RCP8.5. The corresponding reductions in the Brahmaputra Basin are 50 and $70 \%$.

The projected changes in temperature have greater effect on snowfall than the changes in precipitation. When taking into account only changes in precipitation, all snowfall estimates are positive $(\Delta P$, Table 5$)$. This indicates that the mean annual total reduction for each major basin is governed by the temperature change. In some CMIP5 models (values in brackets in Table 5) the effect of precipitation changes $(\Delta P)$ on snowfall are of the same magnitude as the effect of temperature changes $(\Delta T)$; however, for the CMIP5 multimodel mean, temperature changes cause snowfall changes 4-10 times as large as those due to changes in precipitation. This is with reference to the present-day MERRA reference snowfall and for both RCPs2.6 and 8.5. With reference 
to APHRODITE snowfall, the effect of temperature changes compared to precipitation changes is even greater.

\subsection{Regional projections}

If temperatures are far below freezing everywhere, warming may have little effect on snowfall. The same applies if only the highest peaks receive snow today. The largest reduction in snowfall in a basin occurs if today's rain/snow line is at an elevation just below the dominant elevation of the basin. Then large regions will see a shift from snow to rain.

In the Indus Basin, the largest relative snowfall reduction by $2071-2100$ is seen in the southwestern sub-basins, where snowfall is limited today (Fig. 11). The largest total reduction is seen in the snow-rich sub-basins of Kabul/Swat/Alingar in the west and in the east and a smaller reduction in the innermost basins of Gilgit/Hunza, Indus 1 and Nubra/Shyok. Together with the upper regions of the Brahmaputra, these subbasins, clusters I4, I5, B3 and B4 in Fig. 3, were selected for a closer analysis. In addition to having the most snow, these clusters are the most homogeneous when considering the seasonal cycle of snowfall and snow fraction. The values presented in this section are all from the RCP 8.5 for changes from today to 2071-2100.

\subsubsection{Upper Indus, western part}

Cluster 4 consists of the sub-basins Astor, Kabul/Swat/Alingar and Krishen Ganga. As seen from the elevation profile at the top of Fig. 12a the elevation span is large, and there is an almost equal proportion of the terrain at all levels from heights close to sea level to about $5000 \mathrm{~m}$ a.s.l. The most important change for this cluster is a large reduction in the total amount of snowfall in winter and spring.

With a few exceptions, all CMIP5 models project less snowfall in all months of the year (Fig. 12a i, ii). The largest total multi-model mean reduction in snowfall (ii) occurs in February-April, without notable change in the multi-model mean precipitation (iii). Thus, the reduction is caused by increasing temperatures, represented by the rain/snow line in Fig. 12a iv. As seen from the change in the rain/snow line elevation, the projected temperature increase in these months would imply that large areas that receive snow today would receive only rain. About $40 \%$ of the ground in this cluster lies below $2000 \mathrm{~m}$ a.s.l. and receives precipitation as rain throughout the year. In summer, precipitation (iii) is at a minimum, and the rain/snow line (iv) is already so high that only a small fraction of the area receives snowfall today. Thus, although the relative change in snowfall (i) is largest in summer, the change in the amount of snowfall (ii) is small. It should also be noted that the change in the rain/snow line elevation (iv) in summer is much smaller: $400-600 \mathrm{~m}$ compared to 600-900 m in December-April.

\subsubsection{Upper Indus, eastern part}

Further east, the largest changes are projected for the spring season. Cluster 5 in the Indus Basin consists of the sub-basins Gilgit/Hunza, Indus 1, Nubra/Shyok and Zanskar. As shown in Fig. 12b, this is high-elevation terrain, with $80 \%$ of the ground lying above $4000 \mathrm{~m}$ a.s.l. As a result, almost all winter precipitation is snow (Fig. 12b iii). For the multi-model mean, no big changes are projected in January-February. This is partly because of little change in precipitation (iii) and because the rain/snow line (iv) in these months is sufficiently low in the terrain today. With the $500-600 \mathrm{~m}$ shift projected with the RCP8.5, 80-90\% of the area will still have temperatures low enough for snow. The largest changes occur in March-October, when higher temperatures push the rain/snow line above large areas that receive snow today. Increasing summer precipitation (iii) causes the snowfall reduction in summer to be less than it would otherwise be. The effect of higher temperatures is smaller on the APHRODITE snowfall than on the MERRA reference snowfall (ii), as APHRODITE has very little summer snowfall today. The difference arises both from less precipitation (iii) in APHRODITE than MERRA today and from a higher rain/snow line (iv) in APHRODITE. Note that as the change in precipitation was defined as a fraction of the present-day value (Sect. 2.3), the relative changes in APHRODITE and MERRA precipitation are equal.

\subsubsection{Upper Brahmaputra, western part}

In the westernmost part of the upper Brahmaputra Basin, large snowfall changes are projected for the summer. As cluster 5 in the Indus Basin, Brahmaputra's cluster 4 is limited to higher grounds. Less than $6 \%$ lies outside of the 4000 $6000 \mathrm{~m}$ a.s.l. range. The cluster consists of Maquan He, Yarlung Zangbo, Dogxung Zangbo/Maiqu Zangbo., Shang Chu/Yarlung Zangbo/Nyang, Lhasa He/Razheng Zangbo and Yamzho Yumco. The summer monsoon fully dominates the seasonal cycle of precipitation in this region (Fig. 13a iii), resulting in a unimodal snow cycle with a maximum in JulySeptember. In APHRODITE the seasonal cycle of snowfall is similar to, but less pronounced than, the MERRA reference. The summer also sees the greatest reduction in CMIP5 projected snowfall, both in absolute (ii) and relative (i) terms, despite increasing summer precipitation in all models (iii). The reason can be seen from the change in the rain/snow line elevation (iv). In the warmest months, July and August, elevation changes of $400-500 \mathrm{~m}$ would shift the rain/snow line from a level where at least $5-10 \%$ of the ground lies above the line to a level where only $1 \%$ of the area would receive precipitation as snow. In comparison, with reference to MERRA, the $300-400 \mathrm{~m}$ shift seen in January-February would cause only a small absolute change in snowfall (ii) because there is little precipitation in these months (ii) and a small relative change (i) be- 
a)

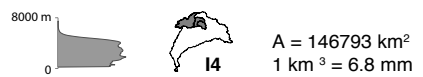

i)

ii)

iii)
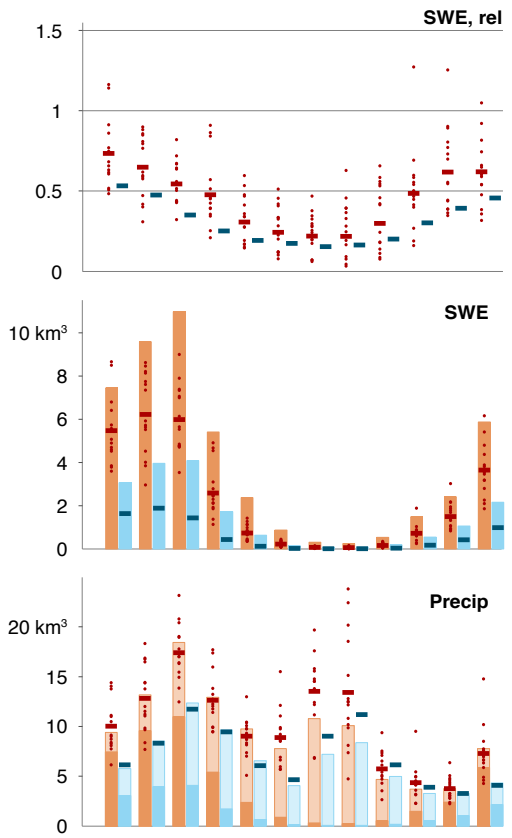

iv)

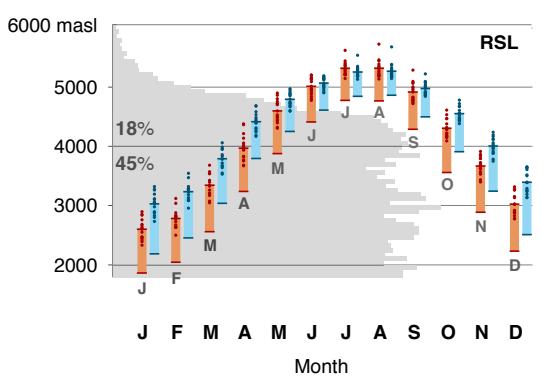

b)
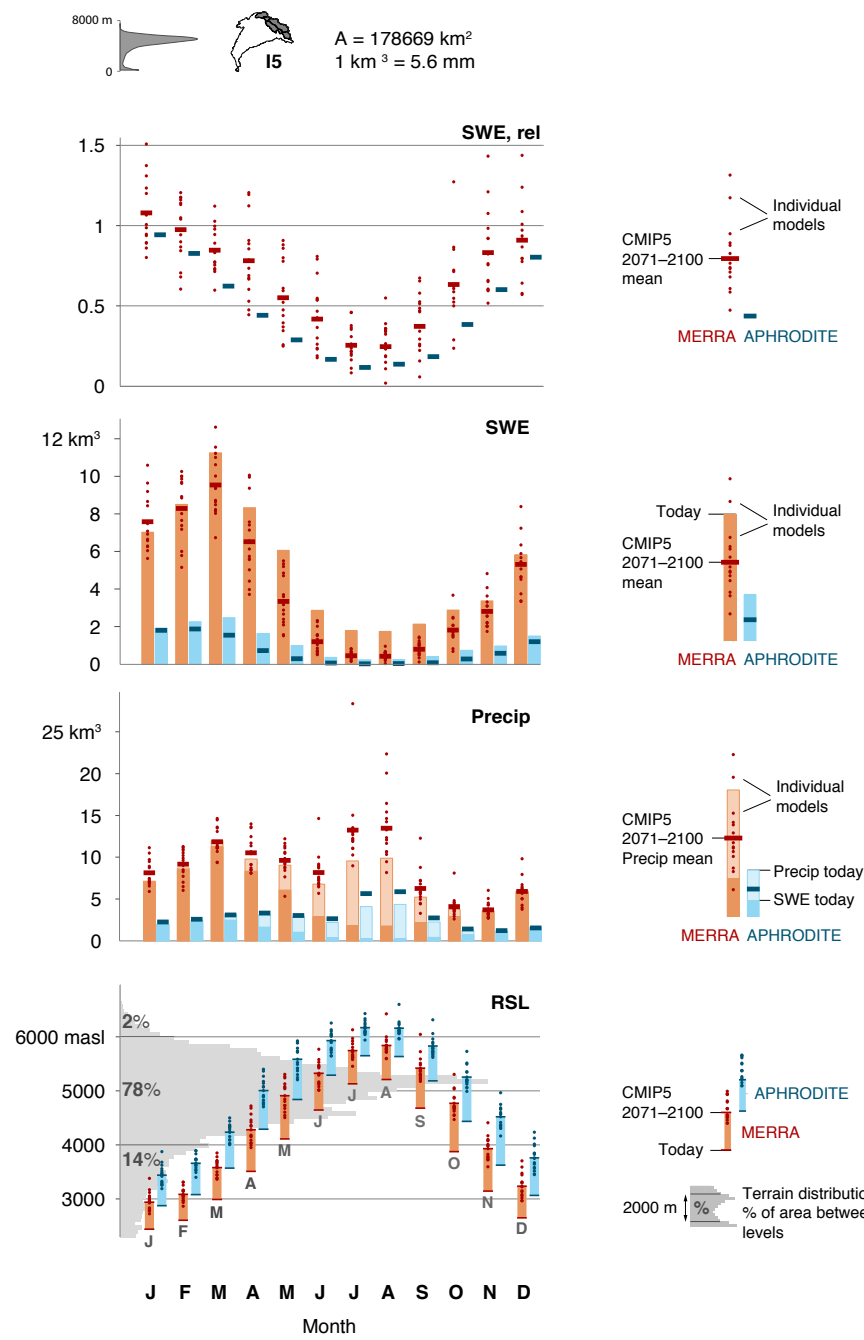

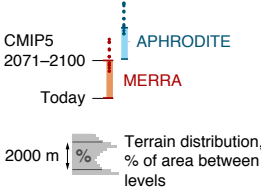

Figure 12. Monthly CMIP5 RCP8.5 change in snowfall, precipitation and rain/snow line elevation in the upper Indus clusters 4 (a) and 5 (b), from 1971-2000 to 2071-2100, with reference to the MERRA reference (red) and APHRODITE (blue). CMIP5 multi-model means are shown as horizontal marks, individual models as dots. Cluster location and terrain profile are shown above the graphs. (i) Fractional change in snowfall. (ii) Future snowfall $\left(\mathrm{km}^{3}\right)$ (dots) compared to today (bars). (iii) Future precipitation $\left(\mathrm{km}^{3}\right)$ (dots), compared to today (bars). Snowfall today is shown as darker parts of bars. (iv) Rain/snow line elevation (m a.s.l.). Gray background indicates elevation histogram with the $\%$ of total ground area lying in the marked $2000 \mathrm{~m}$ intervals. Bars: change from today (bottom panels) to CMIP5 multi-model mean (top panels).

cause the rain/snow line would still be low in the terrain (iv). With reference to APHRODITE, the relative snowfall change in winter would be larger than with reference to MERRA, as temperatures today are higher, resulting in a higher rain/snow line (iv).

\subsubsection{Upper Brahmaputra, eastern part}

Like further west, the Indian summer monsoon dominates the precipitation cycle in the eastern part of upper Brahmaputra (Fig. 13b iii), but the seasonal cycle of snowfall peaks in spring and fall (iii). This is also the time of the largest projected changes.

Cluster 3 in the Brahmaputra consists of the sub-basins Yarlung Zangbo2, Nyang Qu, Yarlung Zangbo3, Yi'ong Zangbo/Parl., Siyom and Zaya Qu/Luhit/Di. About $70 \%$ of the ground lies between 3000 and $6000 \mathrm{ma.s.1.,} \mathrm{but}$ there is also land almost at sea level, mainly in the Zaya $\mathrm{Qu} /$ Luhit/Dingba Qu sub-basin. During summer, most of the terrain lies below the rain/snow line (iv). In spring, temperatures are lower than in summer, and pre- monsoon precip- 
itation is stronger in this part of the Himalayas than further west in cluster 3 (Fig. 13a iii vs. Fig. 13b iii). As a result, March-April gets the most snow.

Reductions in snowfall are projected for all months (ii), comparable in magnitude but largest in the snow-rich spring and late summer. The CMIP5 multi-model mean shows an increase or no change in precipitation in all months (Fig. 13b iii), so the reduction in snowfall is due solely to higher temperatures. The largest absolute reductions, in April and May, occur with a 700-800 m shift in the rain/snow line elevation, leaving $30 \%$ more of the terrain in the rain. The largest relative reduction in future snowfall is projected for July and August (Fig. 13b i), when the rain/snow line shifts so high that only the highest peaks can get precipitation as snow (iv). This would be despite the lowest changes in the rain/snow line: only about $300 \mathrm{~m}$ in APHRODITE.

\subsection{Potential effects of reduced snowfall on water availability}

With a few exceptions, the CMIP5 multi-model mean precipitation change over the coming century is positive in all months in the upper Indus and Brahmaputra (Sect. 4.2). Thus, the projected reduction in snowfall is due solely to higher temperatures. However, there is a large spread in precipitation projections among the models. If temperatures increase as much as projected with the RCP8.5, could any realistic precipitation change in the HKH compensate and maintain present-day snowfall? Results indicate that this may happen in parts of the upper Indus but is out of the reach in the upper Brahmaputra. As for water availability, reduced snowfall may still cause more severe problems in the Indus than in the Brahmaputra.

In cold regions, where temperatures remain below freezing, more winter precipitation may increase both the snow cover area, the length of the snow season and the SWE (Collins et al., 2013; Brutel-Vuilmet et al., 2013; Räisänen, 2008; Gao et al., 2012; Wiltshire, 2014). Räisänen (2008) showed this to be the case in eastern Siberia and the northernmost part of North America. At the southern edge of the seasonal snow cover, relevant for this study, precipitation did not compensate and there was a reduction in SWE. Wiltshire (2014) concluded that there would be small changes in snowfall in very cold and very warm regions of the HKH. Snowfall in Nepal, Bhutan and Himachal Pradesh, where winters are warmer than in most parts of the range, was most vulnerable to higher temperatures. The data presented in Sect. 4.2 generally support the previous studies.

One of the reasons that precipitation does not compensate is that the highest projected precipitation increase in the $\mathrm{HKH}$ is seen in the summer, when the temperature today is so high that only the highest terrain is in the snow zone. Shifting the rain/snow line upward, even by only a few hundred meters, reduces the area that receives snow greatly, requiring very large increases in precipitation to compensate. The summer is the season with the largest relative reduction in snowfall in all the clusters described in Sect. 4.2. Except in the western upper Indus (cluster I4, Sect. 4.2.1), which has very little summer snowfall today, the reduction in summer snowfall is notable in all clusters in the MERRA data and in the Brahmaputra clusters in APHRODITE.

The largest change in snowfall is seen in the western part of the Brahmaputra (cluster B4, Sect. 4.2.3), where a 400$500 \mathrm{~m}$ upward shift in the rain/snow line during summer reduces the area with temperatures low enough for snowfall by a factor of 5-10 (Fig. 13a iv, values not shown). As a result, the summer peak in the seasonal cycle of snowfall is replaced by a dip (Fig. 13a ii). With an even distribution of precipitation with elevation, the area that still receives snow would have to receive 5-10 times as much precipitation to compensate for the lost snowfall. Assuming, more realistically, that precipitation decreases above a certain height, the area would require an even higher increase in precipitation. In the model with the highest increase, a doubling of the July precipitation by the end of the century, SWE is less than $25 \%$ of today's value in that month (Fig. 13a iii).

With a winter-dominated precipitation cycle, the relative change in snowfall is smaller in the upper Indus than in the upper Brahmaputra. Downscaling a high-emission scenario (A1B) in two CMIP3 models with a regional model, Wiltshire (2014) found that by the 2080s precipitation increased more than enough to compensate for higher temperatures in the Karakoram, Hindu Kush and Jammu and Kashmir in one of the models, the HadCM3. In the other model, ECHAM5, precipitation increased less, and snowfall increased only in the higher parts of the Karakoram. In our ensemble of CMIP5 models, multi-model mean precipitation in the upper Indus clusters increases mainly in the summer season when the inter-model spread is also the largest (Figs. 12a iii and b iii). Among the models, 4-5 project increased winter precipitation in the upper Indus, and in the uppermost cluster, I5, this is associated with an increase in winter snowfall (Fig. 12b ii).

Although it is the part of the HKH where snowfall is least reduced by increasing temperatures (Fig. 11b), the Karakoram and inner parts of the upper Indus may still be the region where the changes have the largest impact on river runoff. Compared to the monsoon-dominated regions further east, there is little summer precipitation, and much of the water in the rivers during summer is meltwater (Bookhagen and Burbank, 2010; Immerzeel et al., 2010). As melting of snow and ice has not been analyzed in this study, we cannot quantify the effect of reduced snowmelt on river runoff, but it is obvious that, eventually, reduced snowfall will lead to reduced melting. In western parts of the HKH, this may lead to changes in the seasonal cycle of the river flow.

As pointed out by Wiltshire (2014), increasing precipitation in the eastern $\mathrm{HKH}$ implies that water resources are likely to increase with climate change. As snowfall and snowmelt are both at maximum during summer (Rees and Collins, 2006), meltwater does not have the same importance 
a)

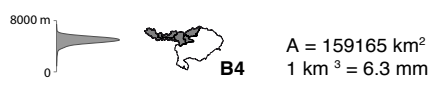

i)

ii)

iii)
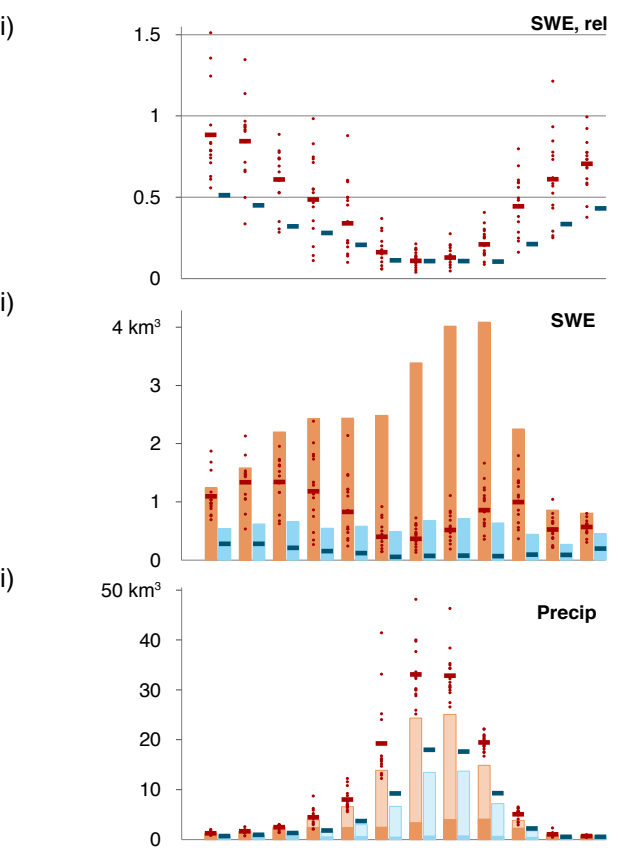

v)

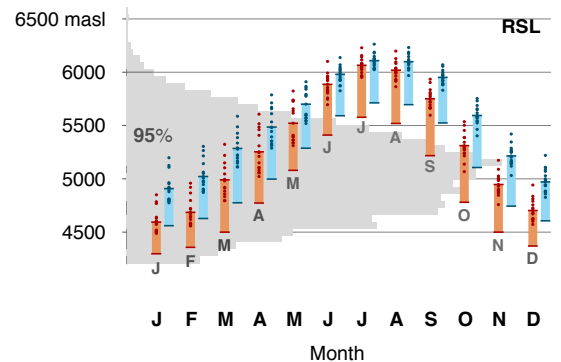

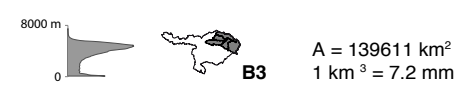

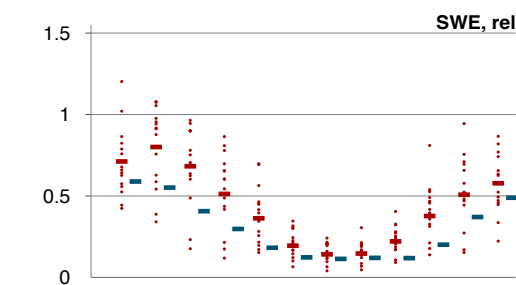

WE, rel
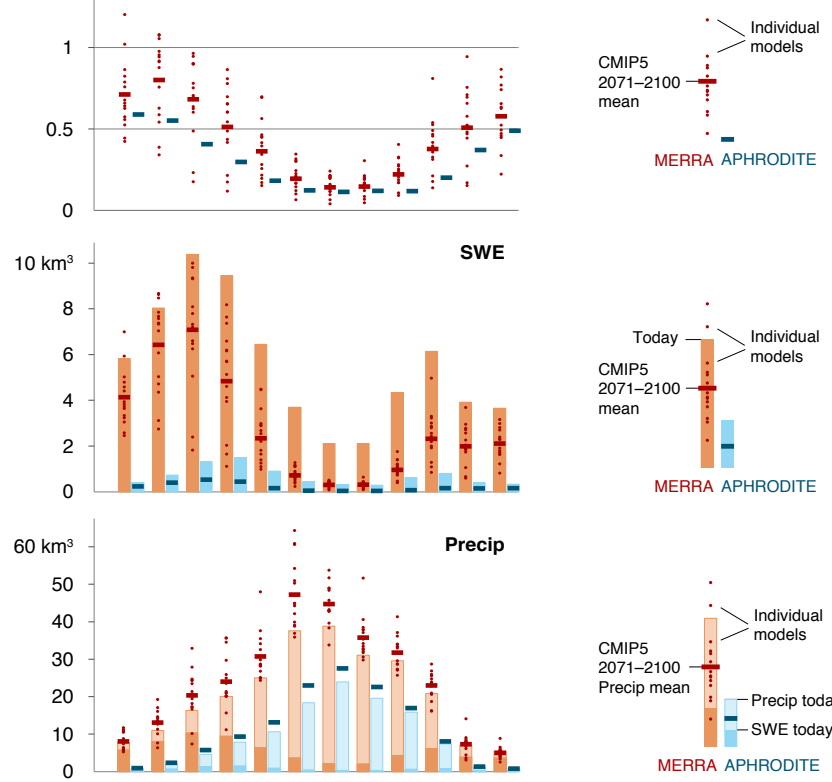

MERRA APHRODITE
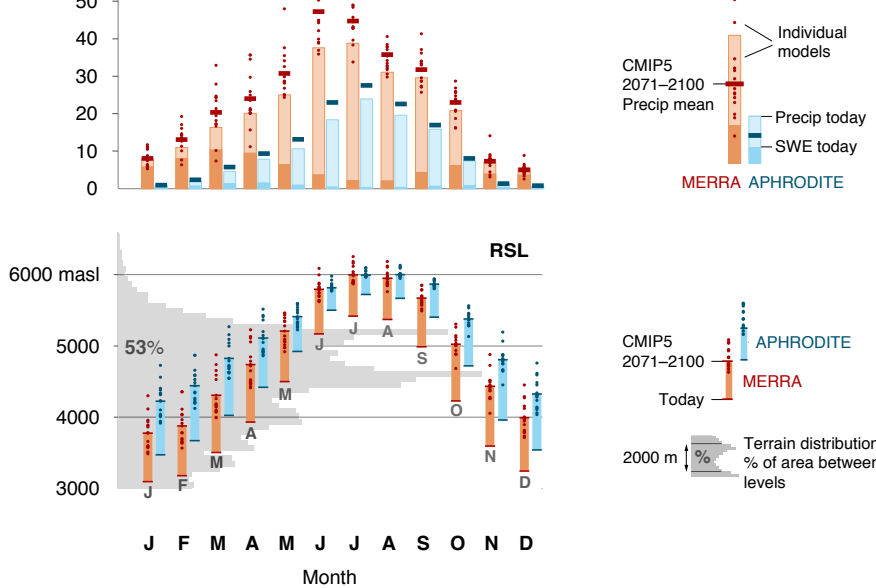

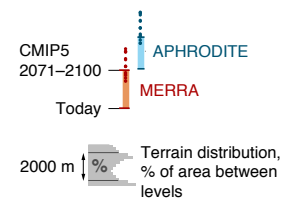

Figure 13. Monthly CMIP5 RCP8.5 change in snowfall, precipitation and rain/snow line elevation in the upper Brahmaputra clusters 4 (a) and 3 (b). See Fig. 12 for a description of the content.

for river flow in dry parts of the year as in the Indus. Reduced snowfall may reduce glaciers, but - not considering potential changes in the amount of evaporation - there is no indication that there will be less water coming from the upper Brahmaputra.

\section{Concluding summary}

In this study we have presented a suite of estimates of present-day snowfall in the Indus, Ganges and Brahmaputra basins and the changes in snowfall that would follow from CMIP5 projected changes in temperature and precipitation from 1971-2000 to 2071-2100. The results show that if the temperature increases as much as in the RCP 8.5 , there will be much less snowfall, despite increasing precipitation in most of the region. Limiting anthropogenic forcing to the RCP2.6 level would still cause reductions, though smaller.

Estimates of present-day snowfall based on a combination of temperature and precipitation from reanalysis data and observations vary by factors of 2-4. The MERRA reanalysis gives higher estimates than TRMM 3B42, CRU TS and APHRODITE; however, the spread is also large between the estimates based on the different observationally based data sets. This demonstrates the difficulties in assessing vulnerability to climate change in the region. With limited knowledge of the current state, future conditions are bound to be uncertain.

Future changes in temperature and precipitation projected by climate models can still provide an indication of the rela- 
tive change in snowfall. With the RCP8.5, the climate models project mean reductions in annual snowfall by $30-50 \%$ in the Indus Basin, 50-60\% in the Ganges Basin and 50-70\% in the Brahmaputra Basin by 2071-2100. With the RCP2.6, the corresponding reductions would be $10-20 \%$ in the Indus, about $20 \%$ in the Ganges and $20-30 \%$ in the Brahmaputra. The reductions are due to increasing temperatures, as the mean of the models show constant or increasing precipitation throughout the year in most of the region.

How much increasing temperatures reduce snowfall in a region depends on how much of the terrain that is below and above the freezing point today and on whether the terrain profile is such that the temperature increase transforms large areas from snow to rain zones. With the RCP8.5, the mean elevation where rain changes to snow - the rain/snow line creeps upward by $400-900 \mathrm{~m}$, in most of the region by 700 $900 \mathrm{~m}$.

The largest relative change in snowfall is seen in the upper westernmost sub-basins of the Brahmaputra, despite increasing precipitation and the lowest rain/snow line elevation change (400-500 m). This is because a major part of this region is near the freezing point today. With the RCP8.5, most of this region will have temperatures above freezing, especially in the summer, which is the wettest part of the year. The projected reduction in annual snowfall is $65-75 \%$.

In the upper Indus, the effect of a warmer climate on snowfall is less extreme, as most of the terrain is high enough to have temperatures sufficiently far below freezing today. Winter and spring brings most of the precipitation, and the projected $600-800 \mathrm{~m}$ change in the rain/snow line elevation during these seasons would leave most of the terrain below the freezing point. Still, a 20-40 \% reduction in annual snowfall is projected with the RCP8.5.

The range of our estimates of present-day snowfall illustrates how little is known about conditions that influence the availability of drinking water in some of the most densely populated parts of the world. There is both a scientific and a societal need for more information about precipitation in the HKH. As a full-scale, long-time observational program covering all parts of the Himalayan range is not a likely possibility, the only hope for improved future knowledge of $\mathrm{Hi}$ malayan snowfall lies in the improvement of satellite data and regional climate models.

\section{The Supplement related to this article is available online at doi:10.5194/tc-9-1147-2015-supplement.}

Acknowledgements. This work has been carried out with support from the University of Bergen, the NORINDIA and SNOWHIM projects funded by The Research Council of Norway and the Centre for Climate Dynamics at the Bjerknes Centre for Climate Research. We acknowledge the World Climate Research Programme's Working Group on Coupled Modelling, which is responsible for CMIP, and we thank the climate modeling groups listed in Table 3 of this paper for producing and making available their model output. For CMIP, the US Department of Energy's Program for Climate Model Diagnosis and Intercomparison provided coordinating support and led development of software infrastructure in partnership with the Global Organization for Earth System Science Portals. We thank Bodo Bookhagen and an anonymous reviewer for valuable and constructive comments that helped us improve the manuscript.

Edited by: R. Brown

\section{References}

Akhtar, M., Ahmad, N., and Booij, M. J.: The impact of climate change on the water resources of Hindukush-KarakorumHimalaya region under different glacier coverage scenarios, J. Hydrol., 355, 148-163, 2008.

Anders, A. M., Roe, G. H., Hallet, B., Montgomery, D. R., Finnegan, N. J., and Putkonen, J.: Spatial patterns of precipitation and topography in the Himalaya, in: Tectonics, Climate, and Landscape Evolution, Geological Society of America Special Paper, edited by: Willett, S. D., Hovius, N., Brandon, M. T., and Fisher, D., Geological Society of America, Boulder, CO, USA, 39-53, 2006.

Archer, D. R. and Fowler, H. J.: Spatial and temporal variations in precipitation in the Upper Indus Basin, global teleconnections and hydrological implications, Hydrol. Earth Syst. Sci., 8, 47-61, doi:10.5194/hess-8-47-2004, 2004.

Bhutiyani, M. R., Kale, V. S., and Pawar, N. J.: Long-term trends in maximum, minimum and mean annual air temperatures across the Northwestern Himalaya during the twentieth century, Climatic Change, 85, 159-177, doi:10.1007/s10584-006-9196-1, 2007.

Bhutiyani, M. R., Kale, V. S., and Pawar, N. J.: Climate change and the precipitation variations in the northwestern Himalaya: 18662006, Int. J. Climatol., 30, 535-548, doi:10.1002/joc.1920, 2010.

Bookhagen, B. and Burbank, D. W.: Topography, relief, and TRMM-derived rainfall variations along the Himalaya, Geophys. Res. Lett., 33, L08405, doi:10.1029/2006GL026037, 2006.

Bookhagen, B. and Burbank, D. W.: Toward a complete Himalayan hydrological budget: Spatiotemporal distribution of snowmelt and rainfall and their impact on river discharge, J. Geophys. Res., 115, F03019, doi:10.1029/2009jf001426, 2010.

Brutel-Vuilmet, C., Ménégoz, M., and Krinner, G.: An analysis of present and future seasonal Northern Hemisphere land snow cover simulated by CMIP5 coupled climate models, The Cryosphere, 7, 67-80, doi:10.5194/tc-7-67-2013, 2013.

Butt, M. J.: Characteristics of snow cover in the Hindukush, Karakoram and Himalaya region using Landsat satellite data, Hydrol. Process., 3689-3698, doi:10.1002/hyp.8375, 2012.

Byun, K. and Choi, M.: Uncertainty of snow water equivalent retrieved from AMSR-E brightness temperature in northeast Asia, Hydrol. Process., 28, 1-12, doi:10.1002/hyp.9846, 2014.

Chaturvedi, R. K., Joshi, J., Jayaraman, M., Bala, G., and Ravindranath, N. H.: Multi-model climate change projections for India under representative concentration pathways, Curr. Sci., 103, 791-802, 2012.

Christensen, J. H., Krishna Kumar, K., Aldrian, E., An, S.-I., Cavalcanti, I. F. A., Castro, M. d., Dong, W., Goswami, P., Hall, A., 
Kanyanga, J. K., Kitoh, A., Kossin, J., Lau, N.-C., Renwick, J., Stephenson, D. B., Xie, S.-P., and Zhou, T.: Climate Phenomena and their Relevance for Future Regional Climate Change, in: Climate Change 2013: The Physical Science Basis, Contribution of Working Group I to the Fifth Assessment Report of the Intergovernmental Panel on Climate Change, edited by: Stocker, T. F., Qin, D., Plattner, G.-K., Tignor, M., Allen, S. K., Boschung, J., Nauels, A., Xia, Y., Bex, V., and Midgley, P. M., Cambridge University Press Cambridge, UK and New York, NY, USA, 1-92, 2013.

Collins, M., Knutti, R., Arblaster, J., Dufresne, J.-L., Fichefet, T., Friedlingstein, P., Gao, X., Gutowski, W. J., Johns, T., Krinner, G., Shongwe, M., Tebaldi, C., Weaver, A. J., and Wehner, M.: Long-term Climate Change: Projections, Commitments and Irreversibility, in: Climate Change 2013: The Physical Science Basis, Contribution of Working Group I to the Fifth Assessment Report of the Intergovernmental Panel on Climate Change, edited by: Stocker, T. F., Qin, D., Plattner, G.-K., Tignor, M., Allen, S. K., Boschung, J., Nauels, A., Xia, Y., Bex, V., and Midgley, P. M., Cambridge University Press, Cambridge, UK and New York, NY, USA, 1-108, 2013.

Cook, E. R., Palmer, J. G., Ahmed, M., Woodhouse, C. A., Fenwick, P., Zafar, M. U., Wahab, M., and Khan, N.: Five centuries of Upper Indus River flow from tree rings, J. Hydrol., 486, 365-375, doi:10.1016/j.jhydrol.2013.02.004, 2013.

Dai, A.: Temperature and pressure dependence of the rain-snow phase transition over land and ocean, Geophys. Res. Lett., 35, L12802, doi:10.1029/2008g1033295, 2008.

Fowler, H. J. and Archer, D. R.: Conflicting Signals of Climatic Change in the Upper Indus Basin, J. Climate, 19, 4276-4293, doi:10.1175/jcli3860.1, 2006.

Gao, J., Williams, M. W., Fu, X., Wang, G., and Gong, T.: Spatiotemporal distribution of snow in eastern Tibet and the response to climate change, Remote Sens. Environ., 121, 1-9, doi:10.1016/j.rse.2012.01.006, 2012.

Gardelle, J., Berthier, E., and Arnaud, Y.: Slight mass gain of Karakoram glaciers in the early twenty-first century, Nat. Geosci., 5, 322-325, 2012.

Guhathakurta, P. and Rajeevan, M.: Trends in the rainfall pattern over India, Int. J. Climatol., 28, 1453-1469, doi:10.1002/joc.1640, 2008.

Guo, L., Turner, A. G., and Highwood, E. J.: Impacts of 20th century aerosol emissions on the South Asian monsoon in the CMIP5 models, Atmos. Chem. Phys. Discuss., 14, 3063930666, doi:10.5194/acpd-14-30639-2014, 2014.

Harris, I., Jones, P. D., Osborn, T. J., and Lister, D. H.: Updated high-resolution grids of monthly climatic observations - the CRU TS3.10 Dataset, Int. J. Climatol., 34, 623-642, doi:10.1002/joc.3711, 2014.

Hartmann, H. and Andresky, L.: Flooding in the Indus River basin - A spatiotemporal analysis of precipitation records, Global Planet. Change, 107, 25-35, doi:10.1016/j.gloplacha.2013.04.002, 2013.

Hastings, D. and Dunbar, P.: Development \& Assessment of the Global Land One-km Base Elevation Digital Elevation Model (GLOBE), ISPRS Commission IV Symposium on GIS - Between Visions and Applications, 7-10 September 1998, Stuttgart, Germany, 1998.
Hastings, D. and Dunbar, P.: Global Land One-kilometer Base Elevation (GLOBE), National Geophysical Data Center, National Oceanic and Atmospheric Administration, United States Department of Commerce, Boulder, Colorado, USA, 1-139, 1999.

Hewitt, K.: The Karakoram Anomaly? Glacier Expansion and the 'Elevation Effect,' Karakoram Himalaya, Mount. Res. Develop., 25, 332-340, doi:10.1659/02764741(2005)025[0332:TKAGEA]2.0.CO;2, 2005.

Huffman, G. J., Adler, R. F., Bolvin, D. T., Gu, G., Nelkin, E. J., Bowman, K. P., Hong, Y., Stocker, E. F., and Wolff, D. B.: The TRMM Multisatellite Precipitation Analysis (TMPA): QuasiGlobal, Multiyear, Combined-Sensor Precipitation Estimates at Fine Scales, J. Hydrometeorol., 8, 38-55, 2007.

Immerzeel, W. W.: Historical trends and future predictions of climate variability in the Brahmaputra basin, Int. J. Climatol., 28, 243-254, doi:10.1002/joc.1528, 2008.

Immerzeel, W. W., Droogers, P., de Jong, S. M., and Bierkens, M. F. P.: Large-scale monitoring of snow cover and runoff simulation in Himalayan river basins using remote sensing, Remote Sens. Environ., 113, 40-49, doi:10.1016/j.rse.2008.08.010, 2009.

Immerzeel, W. W., van Beek, L. P. H., and Bierkens, M. F. P.: Climate Change Will Affect the Asian Water Towers, Science, 328, 1382-1385, doi:10.1126/science.1183188, 2010.

Ines, A. V. M. and Hansen, J. W.: Bias correction of daily GCM rainfall for crop simulation studies, Agr. Forest Meteorol., 138, 44-53, doi:10.1016/j.agrformet.2006.03.009, 2006.

Jain, S. K., Goswami, A., and Saraf, A. K.: Role of Elevation and Aspect in Snow Distribution in Western Himalaya, Water Resour. Manage., 23, 71-83, doi:10.1007/s11269-008-9265-5, 2009.

Kääb, A., Berthier, E., Nuth, C., Gardelle, J., and Arnaud, Y.: Contrasting patterns of early twenty-first-century glacier mass change in the Himalayas, Nature, 488, 495-498, 2012.

Krakauer, N., Pradhanang, S., Lakhankar, T., and Jha, A.: Evaluating Satellite Products for Precipitation Estimation in Mountain Regions: A Case Study for Nepal, Remote Sensing, 5, 41074123, 2013.

Krishna, A. P.: Snow and glacier cover assessment in the high mountains of Sikkim Himalaya, Hydrol. Process., 19, 23752383, doi:10.1002/hyp.5890, 2005.

Kulkarni, A. V., Rathore, B. P., Singh, S. K., and Ajai: Distribution of seasonal snow cover in central and western Himalaya, Ann. Glaciol., 51, 123-128, doi:10.3189/172756410791386445, 2010.

Kumar, V., Rao, Y. S., Venkataraman, G., Sarwade, R. N., and Snehmani: Analysis of Aqua AMSR-E Derived Snow Water Equivalent over Himalayan Snow Covered Regions, Geoscience and Remote Sensing Symposium, 2006, IGARSS 2006, Denver, CO, USA, 702-705, 2006.

Lehner, B., Verdin, K., and Jarvis, A.: New Global Hydrography Derived From Spaceborne Elevation Data, EOS T. Am. Geophys. Un., 89, 93-94, doi:10.1029/2008EO100001, 2008.

MacQueen, J.: Some methods for classification and analysis of multivariate observations, Fifth Berkeley Symposium on Mathematical Statistics and Probability, Berkeley, California, 1-18, 1967.

Ménégoz, M., Gallée, H., and Jacobi, H. W.: Precipitation and snow cover in the Himalaya: from reanalysis to regional climate simulations, Hydrol. Earth Syst. Sci., 17, 3921-3936, doi:10.5194/hess-17-3921-2013, 2013. 
Menon, A., Levermann, A., Schewe, J., Lehmann, J., and Frieler, $\mathrm{K}$.: Consistent increase in Indian monsoon rainfall and its variability across CMIP-5 models, Earth Syst. Dynam., 4, 287-300, doi:10.5194/esd-4-287-2013, 2013.

Moss, R. H., Edmonds, J. A., Hibbard, K. A., Manning, M. R., Rose, S. K., van Vuuren, D. P., Carter, T. R., Emori, S., Kainuma, M., Kram, T., Meehl, G. A., Mitchell, J. F. B., Nakicenovic, N., Riahi, K., Smith, S. J., Stouffer, R. J., Thomson, A. M., Weyant, J. P., and Wilbanks, T. J.: The next generation of scenarios for climate change research and assessment, Nature, 463, 747-756, 2010.

Negi, H. S., Kulkarni, A. V., and Semwal, B. S.: Estimation of snow cover distribution in Beas basin, Indian Himalaya using satellite data and ground measurements, J. Earth Syst. Sci., 118, 525-538, doi:10.1007/s12040-009-0039-0, 2009.

Palazzi, E., v. Hardenberg, J., and Provenzale, A.: Precipitation in the Hindu-Kush Karakoram Himalaya: Observations and future scenarios, J. Geophys. Res.-Atmos., 118, 85-100, 2013.

Räisänen, J.: Warmer climate: less or more snow?, Clim. Dynam., 30, 307-319, doi:10.1007/s00382-007-0289-y, 2008.

Rees, H. G. and Collins, D. N.: Regional differences in response of flow in glacier-fed Himalayan rivers to climatic warming, Hydrol. Process., 20, 2157-2169, doi:10.1002/hyp.6209, 2006.

Rienecker, M. M., Suarez, M. J., Gelaro, R., Todling, R., Bacmeister, J., Liu, E., Bosilovich, M. G., Schubert, S. D., Takacs, L., Kim, G.-K., Bloom, S., Chen, J., Collins, D., Conaty, A., da Silva, A., Gu, W., Joiner, J., Koster, R. D., Lucchesi, R., Molod, A., Owens, T., Pawson, S., Pegion, P., Redder, C. R., Reichle, R., Robertson, F. R., Ruddick, A. G., Sienkiewicz, M., and Woollen, J.: MERRA: NASA's Modern-Era Retrospective Analysis for Research and Applications, J. Climate, 24, 3624-3648, doi:10.1175/JCLI-D-11-00015.1, 2011.

Rikiishi, K. and Nakasato, H.: Height dependence of the tendency for reduction in seasonal snow cover in the Himalaya and the Tibetan Plateau region, 1966-2001, Ann. Glaciol., 43, 369-377, doi:10.3189/172756406781811989, 2006.

Schaner, N., Voisin, N., Nijssen, B., and Lettenmaier, D. P.: The contribution of glacier melt to streamflow, Environ. Res. Lett., 7, 034029, doi:10.1088/1748-9326/7/3/034029, 2012.

Scherler, D., Bookhagen, B., and Strecker, M. R.: Spatially variable response of Himalayan glaciers to climate change affected by debris cover, Nat. Geosci., 4, 156-159, 2011.

Sharif, M., Archer, D. R., Fowler, H. J., and Forsythe, N.: Trends in timing and magnitude of flow in the Upper Indus Basin, Hydrol. Earth Syst. Sci., 17, 1503-1516, doi:10.5194/hess-17-15032013, 2013.

Shekhar, M. S., Chand, H., Kumar, S., Srinivasan, K., and Ganju, A.: Climate-change studies in the western Himalaya, Ann. Glaciol., 51, 105-112, doi:10.3189/172756410791386508, 2010.

Shrestha, A. B., Wake, C. P., Mayewski, P. A., and Dibb, J. E.: Maximum Temperature Trends in the Himalaya and Its Vicinity: An Analysis Based on Temperature Records from Nepal for the Period 1971-94, J. Climate, 12, 2775-2786, doi:10.1175/15200442(1999)012<2775:MTTITH>2.0.CO;2, 1999.

Shrestha, A. B., Wake, C. P., Dibb, J. E., and Mayewski, P. A.: Precipitation fluctuations in the Nepal Himalaya and its vicinity and relationship with some large scale climatological parameters, Int. J. Climatol., 20, 317-327, doi:10.1002/(SICI)10970088(20000315)20:3<317::AID-JOC476>3.0.CO;2-G, 2000.
Siderius, C., Biemans, H., Wiltshire, A., Rao, S., Franssen, W. H. P., Kumar, P., Gosain, A. K., van Vliet, M. T. H., and Collins, D. N.: Snowmelt contributions to discharge of the Ganges, Sci. Total Environ., 9, 468-469, doi:10.1016/j.scitotenv.2013.05.084, 2013.

Singh, P., Jain, S. K., and Kumar, N.: Estimation of Snow and Glacier-Melt Contribution to the Chenab River, Western Himalaya, Mount. Res. Develop., 17, 49-56, doi:10.2307/3673913, 1997.

Singh, P., Kumar, V., Thomas, T., and Arora, M.: Changes in rainfall and relative humidity in river basins in northwest and central India, Hydrol. Process., 22, 2982-2992, doi:10.1002/hyp.6871, 2008.

Sontakke, N. A., Singh, N., and Singh, H. N.: Instrumental period rainfall series of the Indian region (AD 1813-2005): revised reconstruction, update and analysis, Holocene, 18, 1055-1066, doi:10.1177/0959683608095576, 2008.

Sperber, K. R., Annamalai, H., Kang, I. S., Kitoh, A., Moise, A., Turner, A., Wang, B., and Zhou, T.: The Asian summer monsoon: an intercomparison of CMIP5 vs. CMIP3 simulations of the late 20th century, Clim. Dynam., 41, 2711-2744, doi:10.1007/s00382-012-1607-6, 2013.

Tahir, A. A., Chevallier, P., Arnaud, Y., and Ahmad, B.: Snow cover dynamics and hydrological regime of the Hunza River basin, Karakoram Range, Northern Pakistan, Hydrol. Earth Syst. Sci., 15, 2275-2290, doi:10.5194/hess-15-2275-2011, 2011a.

Tahir, A. A., Chevallier, P., Arnaud, Y., Neppel, L., and Ahmad, B.: Modeling snowmelt-runoff under climate scenarios in the Hunza River basin, Karakoram Range, Northern Pakistan, J. Hydrol., 409, 104-117, doi:10.1016/j.jhydrol.2011.08.035, 2011 b.

Taylor, K. E., Stouffer, R. J., and Meehl, G. A.: An Overview of CMIP5 and the Experiment Design, B. Am. Meteorol. Soc., 93, 485-498, doi:10.1175/BAMS-D-11-00094.1, 2011.

Tedesco, M. and Narvekar, P. S.: Assessment of the NASA AMSRE SWE Product, IEEE J. Select. Top. Appl. Earth Observ. Rem. S., 3, 141-159, doi:10.1109/JSTARS.2010.2040462, 2010.

Teutschbein, C, and Seibert, J.: Bias correction of regional climate model simulations for hydrological climate-change impact studies: Review and evaluation of different methods, J. Hydrol., 456457, 12-29, doi:10.1016/j.jhydrol.2012.05.052, 2012.

Turner, A. G. and Annamalai, H.: Climate change and the South Asian summer monsoon, Nat. Clim. Change, 2, 587-595, doi:10.1038/nclimate1495, 2012.

van Vuuren, D., Edmonds, J., Kainuma, M., Riahi, K., Thomson, A., Hibbard, K., Hurtt, G., Kram, T., Krey, V., Lamarque, J.F., Masui, T., Meinshausen, M., Nakicenovic, N., Smith, S., and Rose, S.: The representative concentration pathways: an overview, Climatic Change, 109, 5-31, doi:10.1007/s10584-0110148-z, 2011.

Wang, A. and Zeng, X.: Development of global hourly 0.5-degree land surface air temperature datasets, J. Climate, 26, 7676-7691, doi:10.1175/JCLI-D-12-00682.1, 2013.

Wiltshire, A. J.: Climate change implications for the glaciers of the Hindu Kush, Karakoram and Himalayan region, The Cryosphere, 8, 941-958, doi:10.5194/tc-8-941-2014, 2014.

Winiger, M., Gumpert, M., and Yamout, H.: KarakorumHindukush-western Himalaya: assessing high-altitude water resources, Hydrol. Process., 19, 2329-2338, doi:10.1002/hyp.5887, 2005. 
Xu, X., Lu, C., Shi, X., and Gao, S.: World water tower: An atmospheric perspective, Geophys. Res. Lett., 35, L20815, doi:10.1029/2008GL035867, 2008a.

Xu, Z. X., Gong, T. L., and Li, J. Y.: Decadal trend of climate in the Tibetan Plateau - regional temperature and precipitation, Hydrol. Process., 22, 3056-3065, doi:10.1002/hyp.6892, 2008b.

Yasutomi, N., Hamada, A., and Akiyo, Y.: Development of a Longterm Daily Gridded Temperature Dataset and its Application to Rain/Snow Discrimination of Daily Precipitation, Global Environ. Res., 15, 165-172, 2011.
Yatagai, A., Kamiguchi, K., Arakawa, O., Hamada, A., Yasutomi, N., and Kitoh, A.: APHRODITE: Constructing a Long-Term Daily Gridded Precipitation Dataset for Asia Based on a Dense Network of Rain Gauges, B. Am. Meteorol. Soc., 93, 1401-1415, doi:10.1175/BAMS-D-11-00122.1, 2012.

You, Q., Kang, S., Aguilar, E., and Yan, Y.: Changes in daily climate extremes in the eastern and central Tibetan Plateau during 1961-2005, J. Geophys. Res.-Atmos., 113, D07101, doi:10.1029/2007JD009389, 2008. 